\title{
A Model of NGO Regulation with an Application to Uganda
}

\section{Ronelle Burger}

Corresponding author. Department of Economics, University of Stellenbosch, Private Bag X1, Matieland, 7602, South Africa.

Phone: +27 (0)21 808 2247, Fax:+27 (0)21 808 4637, Email: rburger@sun.ac.za

\section{Indraneel Dasgupta}

Economic Research Unit, Indian Statistical Institute.

\section{Trudy Owens}

School of Economics, University of Nottingham.

Running Title: Regulating NGOs

- We thank an anonymous referee for many helpful comments. We have also benefited greatly from discussions with Anita Dixit, Sripad Motiram, Rupayan Pal, Gideon du Rand and seminar participants at the Indira Gandhi Institute for Development Research, Mumbai. 


\begin{abstract}
:
We develop a model of regulation of service-delivery NGOs, where future grants are conditional on prior spending of some minimal proportion of current revenue on direct project-related expenses. Such regulation induces some NGOs to increase current project spending, but imposes wasteful costs of compliance verification on all NGOs. Under a large class of parametric configurations, we find that regulation increases total discounted project expenditure over a regime of no regulation, when verification costs constitute no more than $15 \%$ of initial revenue. We characterize the optimal regulatory policy under these configurations. We apply our analysis to a large sample of NGOs from Uganda, and find regulation to be beneficial in that context.
\end{abstract}

Keywords: Regulation of non-governmental organizations, developing countries, Uganda

JEL Classification Numbers: I38, L31, L38 


\section{Introduction}

In recent decades, there has occurred an explosive proliferation of non-governmental organizations (NGOs) in developing countries (Anheier and Salamon 2006; Werker and Ahmed 2008). NGOs have come to play a major, often preponderant, role, in delivering developmental services or implementing developmental activities, at the ground level in many poor countries. Foreign donors have increasingly come to transfer aid resources directly to NGOs, instead of governments, while governments themselves have often sought to subcontract out developmental activities to NGOs, instead of utilizing standing bureaucracies. ${ }^{1}$ This expansion in the scope and extent of NGO activities has led to a growing awareness of the importance of assessment and accountability. Consequently, there have been increasingly emphatic proposals for monitoring, regulation and accreditation.

There are a number of types of regulation documented in the literature: donor monitoring, community participation, self-regulation and government regulation (see Burger 2012 for a summary). Donor monitoring and community participation are the least controversial, perhaps because neither concerns the overall NGO sector, but only the individual project that is being funded or received. ${ }^{2}$ Self-regulation however concerns the sector as a whole and has consequently received significant attention (e.g. Gugerty 2008; Prakash and Gugerty 2010; Gugerty, Sidel and Bies 2010). In a sector that is growing, with easy entry, this form of regulation has come about for two core reasons: first, in a competitive funding environment it allows NGOs to send a signal that they are a credible organization; second, it pre-empts potentially harsher regulation by government. Gugerty (2008) identifies three types of self-regulation (national level guilds, NGO led clubs, and voluntary codes of conduct), examines their effectiveness both theoretically and empirically, and concludes that self-regulation is ineffective. Self-regulation requires heterogeneous NGOs to cooperate to produce a public good. It requires independent funding to provide the administrative capacity 
necessary for screening and monitoring. Due to the voluntary nature of this type of regulation enforcement is often difficult and self-selection is a problem (good NGOs are more likely to subscribe than bad ones). Finally, the NGO club has no incentive to expose cases of corruption and ineffectiveness and hence under-regulates for fear of the reputation, and possible revenue, effects for the whole sector. There is therefore potential for government regulation to address these issues.

Representatives of NGOs usually oppose state regulation. Two arguments are typically adduced in articulating such opposition. First, a process whereby NGOs are required to undergo external (government) scrutiny forces them to divert significant amounts of resources from developmental activities to unproductive bureaucratic, 'red-tape' activities such as documentation, official visits, auditing, paper-work, etc. Second, regulatory powers in the hands of politicians and bureaucrats allow them to engage in significant extortion of bribes and/or political support from NGOs. Underlying these arguments is an (often unstated) assumption that most NGOs are both highly efficient and driven by altruistic motives, so that external pressure on them to further improve their performance is likely to generate only minor productivity gains, relative to the costs mentioned earlier. ${ }^{3}$ Governments, on the other hand, tend to argue that NGOs overstate both bureaucratic costs of regulation and the extent of extortion from regulators. Governments further emphasize the idea that many NGOs are inefficient and/or venal: consequently, an external screening mechanism that forces them to improve their performance is likely to generate significant gains relative to its costs.

A process of government regulation typically makes official recognition, or accreditation, of NGOs contingent on their being able to meet some pre-determined minimum performance criteria. NGOs without accreditation face restrictions on access to donors: thus, future access to grants provides incentives to NGOs to meet current accreditation norms. 
Consequently, tighter accreditation requirements may reduce current moral hazard problems to some extent: they may induce some NGOs to improve their current performance, in order to acquire greater donor access in the future. However, other NGOs may deem such norms excessively stringent: they may consequently give up attempts to improve their performance. Thus, the current performance of such NGOs may actually worsen in response to a tightening of accreditation norms. Furthermore, stringent accreditation norms may screen out a large proportion of NGOs, leading to a shortage of NGOs who can be entrusted with future developmental activities, so that donor grants may shift to other countries. A priori, therefore, it is not self-evident that imposing strict accreditation norms will necessarily have a positive impact on aggregate NGO performance, even if we abstract from the issue of bureaucratic dead-weight losses and possible extortion costs associated with regulation emphasized by NGOs themselves.

The problem remains even if, instead of governments, regulation is implemented by some agency affiliated with donors. A large donor, with significant monopsony power in the market for NGOs' services, can expect to engage in repeated interaction with its NGO clients (sellers), and can therefore directly make contract renewal contingent on NGOs meeting some minimal performance norms. In determining such renewal norms, however, the monopsony-donor faces exactly the same trade-offs as those faced by a government regulator. In practice, NGOs typically engage with multiple donors. Consequently, an individual donor may find it prohibitively costly, relative to its expected benefits, to identify an individual NGO's performance history on its own. A standard public goods problem thus exists with regard to independent evaluation of past performance of individual NGOs: the resolution of this problem requires some apex regulatory agency. This regulatory agency can, in principle, either be public or one set up by some association of donors, acting on behalf of donors as a group. Regardless of the exact ownership of the regulatory agency, 
however, the trade-offs it will face in determining what constitutes an acceptable level of past performance remain identical. Even corruption is not unique to public regulation: functionaries of private rating agencies are often accused of dubious assessments for personal gain, while many large international donors such as USAID or faith foundations are routinely charged with using donations to further politico-ideological agendas. Thus, it makes no substantive difference to our analysis whether the regulatory agency is interpreted as a department of a monopsony-donor, a state institution, or an organization run by some apex donor association. In practice, however, even large international donors have limited market power, and donor clubs are typically loose bodies bedevilled by collective action problems. Hence, comprehensive regulatory agencies are more likely to be run by national governments. $^{4}$

The problem of regulating NGOs is structurally different from that of regulating firms operating in a market environment studied in the industrial organization literature. In the latter case, the problem is typically to ensure that firms with market power do not charge consumers a price significantly in excess of their marginal cost: the typical solution is to impose a price cap determined by some regulatory agency, and/or to reduce prices through increased competition by encouraging entry and discouraging market concentration. Since the services provided by NGOs are typically free or heavily subsidized by donor funds, price control is not very relevant. Instead, the problem is to ensure that NGOs use their grant revenues to actually generate desirable outcomes, i.e. to deliver the desired services, in a context where the purchasers and the end users are separate entities. The donor agency, which, in effect, purchases these services on behalf of the end users, cannot directly monitor outputs except at very high cost; while end users cannot directly punish inefficient producers because they do not control the purchase. Thus, the standard literature on regulation in an industrial organization context is of limited direct use in addressing our problem. 
There however exists a small theoretical literature on fund diversion by NGOs to managerial 'perquisite' consumption. Castaneda, Garen and Thornton (2008) develop a model where an exogenous increase in the number of competing non-profit firms reduces fund diversion and increases fundraising. Aldashev and Verdier (2010) endogenize the entry of NGOs and identify conditions under which high fund diversion occurs. Regulation policy in these contributions takes the exclusive, indirect, form of change in the extent of NGO competition through public control over entry. In contrast, we take the size of the NGO sector as given, abstract from fund-raising and thus from NGO competition, and analyze the welfare consequences of public attempts to directly regulate the extent of fund diversion, by making continuation in the NGO sector contingent on keeping fund diversion below some policy determined threshold. The present paper thus complements the analysis in these earlier contributions.

In doing so, we also extend insights generated by the literature on 'conditional charity', i.e., anti-poverty or welfare transfers conditional on prior actions taken by the intended beneficiaries. This literature considers various policy contexts where agents qualify for transfers only if they undertake some prior action or acquire certain characteristics ('targeting indicators') that are deemed by the donor as likely to improve the overall effectiveness of the transfer program in achieving its objective. These actions, much like the regulatory requirements imposed on NGOs: (a) impose costs that may force some agents to opt out of the program, (b) impose costs without improving effectiveness in the case of some who opt in, and (c) impose costs but increase effectiveness in the case of others who opt in. The literature then seeks to aggregate these various costs and benefits to determine whether the overall effectiveness of the transfer program is indeed enhanced by imposing prior conditions or using targeting indicators (see, for example, Dasgupta and Kanbur 2005; 
Bougheas, Dasgupta and Morrissey 2007). The present paper is located broadly within this tradition and adds to it, both theoretically and empirically.

Specifically, our contribution in this paper is two-fold. First, we develop an analytical framework within which the intuitive trade-offs outlined above can be rigorously organized and clarified. This framework allows us to identify a simple empirical rule of thumb, in the form of a transparent sufficiency condition, to determine the contexts where NGO regulation can potentially increase beneficiary welfare. It also allows us to explicitly characterize the optimal form of such regulation under a large class of plausible parametric configurations. Second, we illustrate how these theoretical conclusions may be empirically deployed in a concrete institutional context to derive broad policy conclusions regarding optimal regulation of NGOs. Towards this end, we make use of a large primary data-set on NGO behaviour collected from Uganda to derive the optimal regulation strategy under parametric configurations relevant for that country.

The form of regulation we focus on is an externally mandated lower bound on the share of project-related expenditure in an NGO's budget, which NGOs have to satisfy if they wish to receive government accreditation and thereby qualify for future grants. Thus, future grants are conditional on NGOs taking current actions (i.e. expenditure decisions) to satisfy this lower bound: the share of project-related expenditure is the 'targeting indicator' used to identify NGOs for future transfers. We assume that the objective of public policy is to maximize the present discounted value of total project-related expenditure, while the objective of NGOs is to maximize their utility, which may depend on managerial consumption as well as project-related expenditure. Our focus on the share of project-related expenditure in an NGO's total spending as the targeting indicator reflects both current nonprofit monitoring and regulation practices and public perceptions of effectiveness. Overheads and administrative costs are tracked by watchdog organizations such as GuideStar, the UK 
Charity Commission and the Central Bureau of Fundraising in the Netherlands. Organizations with lower relative overheads and administrative costs receive higher donations, which indicates that this may be an important consideration for donors (Tinkelman 1999; Greenlee and Brown 1999; Bekkers 2003, 2010). Uganda's NGO quality assurance code also proposes that an NGO should calculate the ratio between its overheads and its programme delivery costs to assess its cost effectiveness. ${ }^{5}$

We set up our benchmark model in Section 2. We consider a population of NGOs who differ in their willingness to spend on productive ('project-related') activities, relative to expenditure on unproductive ('managerial') consumption. These NGOs live for two periods and receive identical grants in the first period. An NGO receives a grant in the second period if, and only if, it manages to receive accreditation from some regulatory agency. Accreditation, however, requires the NGO to incur a fixed cost. Furthermore, the regulatory agency makes accreditation contingent on the NGO satisfying a minimal threshold activity criterion, modelled as a minimum share of productive spending in initial budgetary outlay. The distribution of NGO types, i.e. the distribution of project-related expenditure shares that would arise in the absence of any regulation, is common knowledge, but individual NGO type is private knowledge. Thus, in the absence of regulation, a moral hazard problem exists: some NGOs would divert high proportions of their grant income to unproductive managerial consumption. This moral hazard problem is mitigated by setting minimal standards for project-related expenditure as a precondition for receiving accreditation and thereby future grants: such standards provide an incentive to at least some under-performing NGOs to improve their performance. However, regulation in turn generates an adverse selection problem: it imposes unnecessary compliance verification costs on productive NGOs, i.e. NGOs which would meet or exceed these minimal standards even without any regulatory intervention, thereby wasting resources which would otherwise have been spent on projects. 
In this framework, we specify the conditions under which an individual NGO will find it rational to satisfy the accreditation norm.

In Section 3, we first identify conditions that characterize the accreditation threshold that maximizes total discounted productive ('project-related') spending by the NGO population under regulation. We then compare the outcome under such optimal regulation with that under automatic accreditation (i.e., no regulation), which saves the deadweight cost of regulation, but leaves individual NGOs free to divert any proportion of their budget to unproductive consumption. This permits us to characterize sufficient parametric conditions under which optimal regulation dominates automatic accreditation in inducing productive spending. It also yields the following simple rule of thumb: under a large and plausible class of parametric configurations, optimal regulation dominates automatic accreditation unless accreditation costs constitute more than $15 \%$ of initial NGO revenue. Furthermore, putting the threshold project expenditure equal to the normalized present discounted gain from accreditation or unity, whichever is lower, turns out to provide either the optimal regulatory policy or a very close approximation thereof.

Section 4 applies our theoretical conclusions to the policy context of Uganda, to illustrate how they may be operationalized. We use a large primary data-set on NGO activities in Uganda to estimate the key parameters in our model. We then use these estimates to identify the implications for optimal regulatory policy. Section 5 concludes. Detailed proofs are relegated to two Appendices.

\section{The model}

Consider a population of NGOs, each of whom survives for two periods. The size of the NGO population is normalized to unity, and NGOs are indexed by $i \in[0,1] \equiv N$. In period 0 , each NGO $i \in N$ receives a grant of $e_{0}$, which it has to allocate between project expenditure 
$\left(r_{i 0}\right)$ and managerial consumption $\left(m_{i 0}\right)$. At the end of period 0, each NGO has to decide whether to apply for accreditation. If an NGO does apply for accreditation, it has to incur a cost $c>0$ in the next period (period 1). If accredited, it receives a grant $e_{1}$ in period 1 , so that its net income in that period is $\left(e_{1}-c\right)>0$. If it fails to get accredited, or if it does not apply for accreditation, it receives 0 in period $1 .^{6}$ Thus, in the former case, its net income in period 1 is $-c$, while in the latter case it is simply 0 . A period 0 project expenditure share ( $\left.\frac{r_{i 0}}{e_{0}}\right)$ of at least $\underline{\theta} \in[0,1]$ is necessary, but not sufficient, for accreditation: NGOs which meet this norm receive accreditation if, and only if, they incur the verification cost $c .^{7}$ The accreditation threshold $\underline{\theta}$ is determined by an external NGO regulator (e.g. a state body or an independent institution such as an apex donor agency). The verification cost, $c$, is determined by a combination of technical requirements (auditors' fees, costs of documentation, paperwork and accounts maintenance, etc.) and scope for bureaucratic extortion. At the beginning of period $0, \underline{\theta}, c, e_{0}$ and $e_{1}$ are all common knowledge. Thus, if an NGO chooses an initial project expenditure share below $\underline{\theta}$, it is not rational for it to then apply for accreditation. $^{8}$

Preferences of NGO $i$ in each period $k \in\{0,1\}$ are given by:

$$
u^{i}=\min \left\{r_{i k}, a_{i} m_{i k}\right\}
$$

where $r_{i k}$ is project expenditure by the NGO in that period, $m_{i k}$ is managerial consumption, and $a_{i} \in \mathfrak{R}_{++}$is the preference parameter. ${ }^{9}$ NGOs cannot borrow across periods. Denoting by $I_{i 1}$ NGO $i$ 's net income in period 1, and letting $\delta$ denote the common time discount factor, the NGO's two-period maximization problem thus is: 


$$
r_{i 0}, r_{i 1}\left[\min \left\{r_{i 0}, a_{i}\left(e_{0}-r_{i 0}\right)\right\}+\delta \min \left\{r_{i 1}, a_{i}\left(I_{i 1}-r_{i 1}\right)\right\}\right]
$$

subject to:

$$
r_{i 0} \in\left[0, e_{0}\right], r_{i 1} \in\left[0, I_{i 1}\right]
$$

and

$$
I_{i 1}=0 \text { if } \frac{r_{i 0}}{e_{0}}<\underline{\theta} ; I_{i 1}=e_{1}-c>0 \text { otherwise. }
$$

Since NGO $i$ 's utility is maximized in any individual period $k$ by choosing $\hat{r}_{i k}=a \hat{m}_{i k}$, its optimal project expenditure share in every period is:

$$
\hat{\theta}_{i}=\frac{\hat{r}_{i k}}{\hat{m}_{i k}+\hat{r}_{i k}}=\frac{a_{i}}{a_{i}+1}
$$

Since $a_{i} \in \mathfrak{R}_{++}, \hat{\theta}_{i} \in(0,1)$ for all $i \in N$. The variable $\hat{\theta}_{i}$ is distributed over [0,1] according to some continuous and differentiable cumulative distribution function $F(\hat{\theta})$, which yields the corresponding density function $f(\hat{\theta})$. Thus, $F(\hat{\theta})$ provides the distribution of NGO types in the population. While each individual NGO $i$ 's type (the value of $\hat{\theta}_{i}$ ) is private information, the overall distribution of types, $F(\hat{\theta})$, is common knowledge. We shall assume 
that $F(\hat{\theta})=\hat{\theta}^{\alpha}, \alpha \in(0,2]$, so that $f(\hat{\theta})=\alpha \hat{\theta}^{\alpha-1}$. Since the cumulative distribution function is strongly concave (convex) if, and only if, $\alpha<1$ (respectively $\alpha>1$ ), $\alpha<1$ reflects the case where most NGOs wish to spend a relatively low proportion of their budget on project expenses, while $\alpha \in(1,2]$ models the case where most NGOs spend a relatively high proportion of their budget on project expenses. As discussed below in Section 4, the latter case, i.e. $\alpha \in(1,2]$, appears to fit our Ugandan data set.

Noting (2.4), if an NGO decides not to apply for accreditation in period 1, its maximum possible utility is given by: $\left[\hat{u}_{i}=\hat{\theta}_{i} e_{0}\right]$. If it applies for accreditation, then it must spend at least $\underline{\theta} e_{0}$ in period 0 on project expenditure. Two cases are possible.

Case 1: $\hat{\theta}_{i} \geq \underline{\theta}$.

We shall call such NGOs type $\mathrm{H}$ (high). An NGO $i$, when type $\mathrm{H}$, chooses $\hat{\theta}_{i}$ in both periods, applies for and receives accreditation. Lifetime utility for such an NGO is:

$$
\hat{U}_{i}=\hat{\theta}_{i}\left[e_{0}+\delta\left(e_{1}-c\right)\right]
$$

Case 2: $\hat{\theta}_{i}<\underline{\theta}$.

We shall call such NGOs type L (low). Type L NGOs have to decide whether to reveal their type in period 0 by choosing their respective $\hat{\theta}_{i}$, or disguise it by choosing $\underline{\theta}$. By choosing $\underline{\theta}$ in period 0 , a type L NGO ensures accreditation, which allows it to receive $\left(e_{1}-c\right)$ and choose its $\hat{\theta}_{i}$ in period 1. Since, by (2.4), $a_{i}=\frac{\hat{\theta}_{i}}{1-\hat{\theta}_{i}}$, a type L NGO's lifetime utility from pretending to be type $\mathrm{H}$ is: 


$$
\begin{gathered}
\hat{U}_{i}=\left[a_{i}(1-\underline{\theta}) e_{0}+\delta \hat{\theta}_{i}\left(e_{1}-c\right)\right]=\left[\frac{\hat{\theta}_{i}}{1-\hat{\theta}_{i}}(1-\underline{\theta}) e_{0}+\delta \hat{\theta}_{i}\left(e_{1}-c\right)\right] \\
=\hat{\theta}_{i} e_{0}\left[1-\frac{\left(\underline{\theta}-\hat{\theta}_{i}\right)}{\left(1-\hat{\theta}_{i}\right)}\right]+\delta \hat{\theta}_{i}\left(e_{1}-c\right) .
\end{gathered}
$$

Thus, in effect, the accreditation requirement imposes the equivalent of a monetary loss of $e_{0} \frac{\left(\underline{\theta}-\hat{\theta}_{i}\right)}{\left(1-\hat{\theta}_{i}\right)}$ on a type L NGO in period 0 , in exchange for a monetary gain in period 1 , whose present discounted value is $\delta\left(e_{1}-c\right)$ : if the NGO chooses to reveal its type in period 0 , it only receives $\hat{\theta}_{i} e_{0}$. Using (2.6), for a type L NGO, net lifetime gain from mimicking a type $\mathrm{H}$ one in period 0 (i.e. choosing $\underline{\theta}$ instead of $\hat{\theta}_{i}$ ) is therefore:

$$
\Pi_{i}=\hat{\theta}_{i} e_{0}\left[\frac{\delta\left(e_{1}-c\right)}{e_{0}}-\frac{\left(\underline{\theta}-\widehat{\theta}_{i}\right)}{\left(1-\widehat{\theta}_{i}\right)}\right]
$$

Define $\Omega \equiv \frac{\delta\left(e_{1}-c\right)}{e_{0}}$. Thus, $\Omega$ is simply the net present value of the benefit from accreditation, expressed as a proportion of the initial grant revenue. Then, from (2.7),

$$
\Pi_{i} \geq 0 \text { iff }\left[\Omega \geq \frac{\left(\underline{\theta}-\hat{\theta}_{i}\right)}{\left(1-\hat{\theta}_{i}\right)}\right]
$$

The condition in (2.8) simply states that the normalized net present value of the benefit from accreditation should at least cover the normalized period 0 loss from accreditation for a type L NGO, if such an NGO is to be induced to seek accreditation. Since, for a type L NGO, 
$\hat{\theta}_{i}<\underline{\theta}$, the normalized loss $\frac{\left(\underline{\theta}-\hat{\theta}_{i}\right)}{\left(1-\hat{\theta}_{i}\right)}$ is positive; furthermore, this expression is decreasing in $\hat{\theta}_{i}$ for all $\underline{\theta}<1$. Hence (recalling $\hat{\theta}_{i}>0$ ), given any $\underline{\theta}<1, \frac{\left(\underline{\theta}-\hat{\theta}_{i}\right)}{\left(1-\hat{\theta}_{i}\right)} \in(0, \underline{\theta})$. Given positive benefit from accreditation ( $\Omega>0$ ), and recalling (2.8), we have the following.

Lemma 2.1. Let $\tilde{\theta} \equiv \frac{\underline{\theta}-\Omega}{1-\Omega}$. Then:

(i) if $\underline{\theta} \leq \Omega$, all NGOs with $\hat{\theta}_{i} \in[0, \underline{\theta}]$ choose $\underline{\theta}$ in period 0 , while all NGOs with $\hat{\theta}_{i}>\underline{\theta}$ choose $\hat{\theta}_{i}$;

(ii) if $\underline{\theta}>\Omega$, then all NGOs with either $\hat{\theta}_{i}<\tilde{\theta}$ or $\hat{\theta}_{i}>\underline{\theta}$ choose $\hat{\theta}_{i}$ in period 0 , while all NGOs with $\hat{\theta}_{i} \in[\tilde{\tilde{\theta}}, \underline{\theta}]$ choose $\underline{\theta}$.

By Lemma 2.1(i), if the minimum project expenditure share required is lower than the (normalized) benefit from accreditation, all type L NGOs choose that threshold level. By Lemma 2.1(ii), if the minimum project expenditure share required for accreditation is greater than the benefit from doing so, NGOs which prefer very high managerial consumption find it too costly to mimic type H NGOs in period 0. Such NGOs therefore reveal their type, even though this entails losing the grant in period $1 .^{10}$

For any arbitrary level of regulation $\underline{\theta} \in[0,1]$, Lemma 2.1 in effect characterizes the supply function for accredited NGOs in a competitive market for NGOs' services. We think of individual NGOs as competitive price-taking sellers in the global market for developmental services, and of the amounts $e_{0},\left(e_{1}-c\right)$ (and, therefore, also the normalized net benefit from accreditation, $\left.\Omega \equiv \frac{\delta\left(e_{1}-c\right)}{e_{0}}\right)$ as such competitive 'prices'. In this market, 
individual NGOs take these prices as given and determine, on the basis of such prices, their own preferences (i.e., the relative weight they put on managerial consumption) and the stringency of the accreditation norm $(\underline{\theta})$, whether to achieve accreditation. The aggregate of these individual decisions determines the size of the total NGO population that achieves accreditation and is therefore available to receive grants $\left(e_{1}\right)$ in the next period. Thus, decentralized utility maximization by atomistic NGOs generates the aggregate supply function for accredited NGOs:

$$
N_{S}=N_{S}\left(\underline{\theta}, e_{0}, e_{1}, c\right)
$$

with the properties of the function $N_{S}($.$) explicated by Lemma 2.1$.

We close our specification of the market for accredited NGOs by assuming that the inverse demand function for such NGOs is given by $N_{D}(n)$, with $N^{\prime}{ }_{D} \leq 0, N_{D}(1)>c$ and $\delta\left(\frac{N_{D}(0)-c}{e_{0}}\right)<1$. Thus, given any accredited NGO population $n \in[0,1]$, every accredited NGO would receive a grant of exactly $N_{D}(n)$, so that the period 1 grant would simply be $e_{1}=N_{D}(n)$. Furthermore, for every $n \in[0,1], e_{1}>c$ and $\Omega<1$. We think of the aggregate demand for accredited NGOs, summarized by the inverse demand function $N_{D}(n)$, as generated by some prior process of utility maximization by price-taking donors, who act as atomistic buyers in the global market for NGOs' services. While we do not explicitly model this process here, it is intuitively clear that the demand for the services of accredited NGOs will be determined by a combination of donor budgets, preferences and competition from other market segments, i.e., from NGOs in other countries or regions. The greater such competition (i.e. the greater the extent of substitution by donors across market segments), the more elastic the demand. 
In our welfare analysis in subsequent sections, we shall assume that the NGOs in a particular country or region form a very small, easily substitutable, part of the global NGO market, so that, in effect, they face (individually as well as collectively) a perfectly elastic demand function, with the return to accreditation determined in the larger global market. This competitive 'small country' assumption, standard in trade theoretic analyses for developing countries such as Uganda, seems natural and appropriate for the NGO sectors of these countries as well, which constitute a very small part of the global NGO sector. Hence, we shall assume that the grant available to an accredited NGO, $e_{1}$, is independent of the number of NGOs receiving accreditation. Thus, if providing $e_{1}$ to each accredited NGO does not exhaust the donor's budget, the surplus reverts back to the donor, instead of being divided among the accredited NGOs. In practice, NGOs typically have limited organizational ability, so that their ability to deliver on projects diminishes sharply once the project size crosses a certain threshold. Consequently, any additional grant beyond some threshold is mostly used for managerial consumption by all NGOs. Knowing this, donors often prefer to shift surplus funds to other uses, say NGOs in other countries/regions/sectors, instead of significantly increasing grants to individual NGOs in the accredited pool. Note however that our analysis can be easily generalized to the 'large country' case, as we shall discuss in Remark 3.4 below.

Regardless of its exact elasticity, the demand function for accredited NGOs combines with the supply function, characterized by Lemma 2.1, to determine the second period grant, say $e_{1}^{*}$, and the size of the accredited NGO population, that must obtain in equilibrium. Regulatory changes in the accreditation threshold, by shifting the supply function, may change the equilibrium value of one or both of these variables, thereby affecting the present discounted value of aggregate project expenditure. Our problem of deriving the optimal regulatory policy thus depends on the exact way in which the supply function shifts in response to a change in the accreditation threshold. 
The basic structure of our problem, as outlined above, can be clarified further via Figure 1.

\section{Insert Figure 1 here.}

Recall that $\Omega$ is the net present value of the benefit from accreditation, expressed as a proportion of the initial grant revenue; thus, $\Omega \equiv \frac{\delta\left(e_{1}-c\right)}{e_{0}}$. Hence, given the parameters $\delta, c, e_{0}$, for all $\underline{\theta} \in[0,1]$, we can define the function $T(\underline{\theta}) \equiv\left[\underline{\theta}\left(\frac{e_{0}}{\delta}\right)+c\right]$, which yields the value of $e_{1}$ at which $\underline{\theta}=\Omega$. Evidently, $T($.$) is increasing in \underline{\theta}$, with $T(0)=c$. Thus, given any $\underline{\theta} \in[0,1], \underline{\theta}<\Omega$ if $e_{1}>T(\underline{\theta})$ and $\underline{\theta}>\Omega$ if $e_{1}<T(\underline{\theta})$. Lemma 2.1(i) therefore implies that, given the parameters $\delta, c, e_{0}$, and given any $\underline{\theta} \in[0,1]$, the supply schedule for accredited NGOs is vertical at unity for $e_{1} \in[T(\underline{\theta}), \infty)$. Since the cumulative distribution function for NGO types, $F(\hat{\theta})$, is continuous and increasing, noting that (i) $\tilde{\theta}=\underline{\theta}$ at $e_{1}=c$, and (ii) whenever $\underline{\theta} \in(0,1), \tilde{\theta}$ is decreasing in $e_{1}$ for $e_{1} \in(c, T(\underline{\theta}))$, we get the following shape for the supply schedule of accredited NGOs from Lemma 2.1(ii). Since, at $e_{1}=c$, an NGO receives accreditation if and only if $\theta_{i} \geq \underline{\theta}$, total supply of accredited NGOs is [1 $F(\underline{\theta})]$. For all $\underline{\theta} \in(0,1)$, such supply is increasing in $e_{1}$ for $e_{1} \in(c, T(\underline{\theta}))$, and, as already noted, is constant at unity for all $e_{1} \geq T(\underline{\theta})$. Obviously, supply is zero if $e_{1}<c$.

Since $T(0)=c$, in the limiting case of $\underline{\theta}=0$, supply is unity for all $e_{1} \geq c$. In the other limiting case of $\underline{\theta}=1$, supply is 0 for all $e_{1}<T(1)$. As $\underline{\theta}$ increases, the supply schedule shifts up and to the left. Figure 1 illustrates possible supply schedules for accredited NGOs when $\underline{\theta}$ takes the values $1 / 4,1 / 2$, and $3 / 4$, with the schedules more to the left representing higher values of $\underline{\theta}$. 
Define $\dddot{\theta} \equiv T^{-1}\left(N_{D}(1)\right)$; since we assume $N_{D}^{\prime} \leq 0$, and $\delta\left(\frac{N_{D}(0)-c}{e_{0}}\right)<1$, we must have $\dddot{\theta} \in(0,1)$. The schedule DD' in Figure 1 illustrates a possible (less than perfectly elastic) demand function for accredited NGOs faced by the regulator, with $\dddot{\theta}=\frac{1}{4}$. Evidently, when the regulator chooses any accreditation threshold $\underline{\theta} \in[0, \dddot{\theta}]$, the entire NGO population achieves accreditation in equilibrium, so that the equilibrium supply of accredited NGOs is unity. The equilibrium value of period 1 grant is then $e_{1}^{*}=T(\dddot{\theta})$. The equilibrium supply of accredited NGOs monotonically falls, and the equilibrium value of period 1 grant monotonically rises, with any increase in the value of the regulatory threshold $\underline{\theta}$ in the interval $(\dddot{\theta}, 1)$. Since $\delta\left(\frac{N_{D}(0)-c}{e_{0}}\right)<1$, the former attains the value 0 when $\underline{\theta}=1$.

Evidently, if the demand function is assumed instead to be perfectly elastic at $e_{1}^{*}=T(\ddot{\theta})$, then the claim made above regarding the relationship between the equilibrium supply of accredited NGOs and the accreditation threshold must continue to hold. However, the equilibrium value of period 1 grant must now remain invariant throughout at $e_{1}^{*}$ with respect to the accreditation threshold.

\section{Optimal regulation}

Is total discounted project expenditure maximized by 'automatic accreditation', in the sense of a complete absence of regulation? Such a laissez faire policy vis-à-vis the NGO sector eliminates the deadweight costs associated with bureaucratic verification of NGO claims regarding their expenditure pattern. However, it also induces some NGOs to choose high managerial consumption in the initial period. Conversely, a policy of external regulation, whereby the regulator makes accreditation (and thus grant renewal) contingent on the NGO meeting some positive threshold requirement of initial project expenditure, may reduce initial managerial consumption, but incurs deadweight costs of verification. To assess the case for 
automatic accreditation, i.e. non-regulation, therefore, one has to identify the optimal regulatory outcome under costly regulation, and compare this with the outcome under nonregulation. We now proceed to address this issue. We first identify the optimal accreditation norm under a regime of costly regulation. We then compare the total discounted project expenditure generated by this norm with that generated by non-regulation. This exercise allows us to specify parametric conditions under which non-regulation may be dominated by regulation, and to characterize optimal regulation under a large class of empirically plausible parametric configurations.

Suppose that the NGO regulator faces a given demand schedule for accredited NGOs (independent of accreditation norms chosen by the regulator), determined by the aggregate behaviour of donors (global purchasers of NGOs' services), and wishes to maximize the present discounted value of total project expenditure over the two periods. ${ }^{11}$ How should it choose the threshold level of initial project expenditure, $\underline{\theta}$, as its accreditation norm?

\subsection{Optimal project expenditure threshold under costly regulation}

Suppose $\Omega<1$. When $\underline{\theta} \leq \Omega<1$, by Lemma 2.1(i), total (discounted) project expenditure is:

$$
J=e_{0}\left[\underline{\theta} F(\underline{\theta})+\int_{\underline{\theta}}^{1} \hat{\theta}_{i} f\left(\hat{\theta}_{i}\right) d \hat{\theta}_{i}+\Omega \int_{0}^{1} \hat{\theta}_{i} f\left(\hat{\theta}_{i}\right) d \hat{\theta}_{i}\right]
$$

When $\underline{\theta} \in[\Omega, 1]$, by Lemma 2.1(ii), total (discounted) project expenditure is:

$$
J=e_{0}\left[\int_{0}^{\widetilde{\theta}} \hat{\theta}_{i} f\left(\hat{\theta}_{i}\right) d \hat{\theta}_{i}+\underline{\theta}(F(\underline{\theta})-F(\tilde{\theta}))+\int_{\underline{\theta}}^{1} \hat{\theta}_{i} f\left(\hat{\theta}_{i}\right) d \hat{\theta}_{i}+\Omega \int_{\widetilde{\theta}}^{1} \hat{\theta}_{i} f\left(\hat{\theta}_{i}\right) d \hat{\theta}_{i}\right] .
$$

First notice that, if $\underline{\theta}<\Omega<1$, (3.1) implies $\frac{d J}{d \underline{\theta}}>0$. Hence, we have the following. 
Lemma 3.1. Given regulation, and given any $\Omega \in(0,1)$, total discounted project expenditure is maximized only if $\underline{\theta} \geq \Omega$.

A marginal rise in the accreditation threshold $(\underline{\theta})$, from any value below the normalized net present value of the benefit from accreditation $(\Omega)$, forces some NGOs (intuitively, those with very high relative valuation of managerial consumption) to spend more on projects in period 0. All NGOs, however, continue to find accreditation profitable (Lemma 2.1(i)). Hence, total project expenditure in period 0 increases, while such expenditure in period 1 remains constant. From any initial $\underline{\theta}<\Omega$, the net effect of a marginal tightening of accreditation norms thus has an unambiguously positive effect on total project expenditure. It follows that optimal regulation cannot involve choosing any accreditation threshold below the normalized net benefit from accreditation.

Figure 1 clarifies this conclusion. As already noted, it illustrates a situation where donor demand for accredited NGOs is such that equilibrium supply is less than unity for all accreditation thresholds $\underline{\theta}>\frac{1}{4}$, and exactly equal to unity for all $\underline{\theta} \leq \frac{1}{4}$. Within the latter interval $\left(0, \frac{1}{4}\right]$, an increase in the accreditation threshold does not change equilibrium supply of accredited NGOs, and, therefore, it does not change the equilibrium value of period 1 grant $\left(e_{1}\right)$. Hence, the optimal regulatory policy cannot involve a threshold level below 1/4. Recalling that $T(\underline{\theta})$ yields the value of $e_{1}$ at which $\underline{\theta}=\Omega$, and letting $e_{1}^{*}$ denote the price (i.e., period 1 grant level) at which donor demand for accredited NGOs is unity, we can generalize this observation to the claim that the optimal regulatory threshold cannot be less than $T^{-1}\left(e_{1}^{*}\right)$ (Lemma 3.1). Note that Lemma 3.1 holds independently of any assumption regarding the elasticity of demand. 
From (3.2), it is clear that the situation gets more complicated when the accreditation threshold exceeds the gains from accreditation (i.e, $\underline{\theta}>\Omega$, implying $e_{1}<T(\underline{\theta})$ ). Recall Lemma 2.1(ii) and Figure 1. A marginal rise in the accreditation threshold now induces more NGOs to reveal their type. At the same time, it also induces some NGOs to spend more on projects in period 0 . The two effects contradict one another in terms of their impact on aggregate project expenditure in the initial period. The first effect, by reducing the supply of accredited NGOs, also reduces total project expenditure by all NGOs in the next period when demand is sufficiently elastic (note the last term in (3.2), which denotes total discounted project expenditure in period 1). ${ }^{12}$ A priori, the overall effect on aggregate project expenditure thus appears ambiguous, regardless of the elasticity of demand.

Intuitively, it is clear that the exact form of the cumulative distribution of NGOs would have a crucial bearing on the aggregate outcome. Recall that $F(\hat{\theta})=\hat{\theta}^{\alpha}, \alpha>0$, so that $f(\hat{\theta})=\alpha \hat{\theta}^{\alpha-1}$; the parameter $\alpha \in(0,2]$ determines the exact form of the distribution. Then (3.2) above reduces to:

$$
\begin{aligned}
& J=e_{0}\left[\alpha \int_{0}^{\tilde{\theta}} \hat{\theta}^{\alpha} d \hat{\theta}+\underline{\theta}\left(\underline{\theta}^{\alpha}-\tilde{\theta}^{\alpha}\right)+\alpha \int_{\underline{\theta}}^{1} \hat{\theta}^{\alpha} d \hat{\theta}+\Omega \alpha \int_{\tilde{\theta}}^{1} \hat{\theta}^{\alpha} d \hat{\theta}\right] \\
& =e_{0}\left[\frac{\alpha \tilde{\theta}^{\alpha+1}}{\alpha+1}+\left(\underline{\theta}^{\alpha+1}-\underline{\theta}^{\alpha}\right)+\frac{\alpha\left(1-\underline{\theta}^{\alpha+1}\right)}{\alpha+1}+\Omega \frac{\alpha}{\alpha+1}\left(1-\tilde{\theta}^{\alpha+1}\right)\right] \\
& =e_{0}\left[\left(\frac{\alpha \tilde{\theta}^{\alpha+1}+\underline{\theta}^{\alpha+1}-\alpha \Omega \tilde{\theta}^{\alpha+1}}{\alpha+1}\right)-\underline{\theta}^{\alpha}\right]+\left(\frac{\alpha e_{0}}{\alpha+1}\right)(\Omega+1) ;
\end{aligned}
$$

where, recalling Lemma 2.1, $\tilde{\theta} \equiv \frac{\underline{\theta}-\Omega}{1-\Omega}$.

The second determinant of the welfare consequences of regulation would of course be the elasticity of demand. We abstract from the second effect at this stage, by assuming 
perfectly elastic demand (and hence, an exogenously given value of second period grant $e_{1}$ ), in order to concentrate on the first. As discussed in detail in Remark 3.4 below, our analysis can be easily extended to the case of less than perfectly elastic demand. Evidently, unit elastic demand, i.e. a fixed total grant budget in period 1, would constitute a special case of less than perfectly elastic demand.

Manipulating (3.3), and recalling Lemma 3.1, we can conclude the following regarding the optimal regulatory choice of the accreditation threshold $(\underline{\theta})$.

Proposition 3.2. Suppose the demand for accredited NGOs in period 1 is perfectly elastic. Then, given regulation, and given any $\Omega \in(0,1)$,

(i) there exists $\lambda \in(0,1-\Omega)$ such that total discounted project expenditure is maximized only if $\underline{\theta} \in[\Omega, 1-\lambda]$;

(ii) there exists $\varepsilon \in(0,1)$ such that, for all $\alpha \in(1-\varepsilon, 1+\varepsilon)$, total discounted project expenditure is uniquely maximized by $\underline{\theta}=\Omega$;

(iii) there exists $\eta \in(0,1)$ such that, for all $\alpha \in(1+\eta, 2]$, total discounted project expenditure is uniquely maximized by some $\underline{\theta} \in(\Omega, 1)$.

Proof: See Appendix 1.

Recall our earlier discussion of the effects of greater regulation, as summarized by equation (3.2). As noted there, increasing the stringency of accreditation norms has two possible negative effects on total discounted project expenditure. First, this may induce some NGOs to stop trying to meet accreditation norms altogether: such NGOs would reduce their project expenditure in period 0 . Second, since such NGOs would not qualify for grants in the next period, the available pool of NGOs receiving grants in period 1 would shrink. This shrinkage implies total revenue received by the NGO sector as a whole in period 1 would 
decline as a consequence of tighter regulation when demand is elastic. Proposition 3.2 identifies how these two negative effects, along with the deadweight losses from regulation, interact with possible positive effects on initial project spending, to determine the optimal regulatory policy under our 'small country' assumption for the NGO sector.

By Proposition 3.2(i), if $0<\Omega<1$, the optimal regulatory policy threshold must always permit NGOs to divert a positive proportion of their funds to unproductive managerial consumption. It is possible for regulation to reduce fund diversion to an 'excessive' extent: increasing the regulatory threshold becomes counter-productive beyond a point. This happens because such a policy induces far too many NGOs to forgo accreditation. Consequently, these NGOs spend less on projects in the initial period, compared to what they would have done under a somewhat less demanding accreditation norm. Additionally, project expenditure in the subsequent period is reduced because these NGOs find it rational not to attempt to meet such a stringent criterion.

Recall that, by Lemma 2.1(ii), NGOs which prefer very high levels of managerial consumption will choose to forgo accreditation when the accreditation threshold exceeds the gains from accreditation (i.e. $\underline{\theta}>\Omega$ ). By Proposition 3.2(ii), when $\alpha$ is sufficiently close to 1 (i.e. the distribution of NGO types is roughly uniform), all NGOs must be induced to meet the accreditation norm, if project expenditure is to be maximized. Hence, recalling Lemma 3.1, the accreditation norm $\underline{\theta}$ must be set at $\Omega$ : any further increase will induce some NGOs to increase their initial managerial consumption and drop out of the accreditation process. This negative effect on aggregate project expenditure will outweigh any positive effect in terms of higher first period spending by other NGOs.

By Proposition 3.2(iii), when $\alpha$ is sufficiently close to 2 (i.e. most NGOs prefer relatively low levels of managerial consumption), the project expenditure maximizing value of $\underline{\theta}$ is greater than the benefit from accreditation $\Omega$, so that some NGOs will find it rational 
not to meet the accreditation criterion (Lemma 2.1(ii)). Hence, not all NGOs will receive a positive income in period 1. Despite the consequent reduction in total project expenditure, such a relatively high accreditation norm would be beneficial overall, since it forces some NGOs to spend more on projects initially. This latter, positive, effect outweighs the first two, negative, effects on project spending.

Remark 3.3. If $\Omega \geq 1,(2.8)$ implies $\Pi_{i} \geq 0$ regardless of type $\left(\hat{\theta}_{i}\right)$. Thus, in this case, all NGOs apply for and receive accreditation, regardless of the norm $\underline{\theta}$. Evidently, the total project expenditure maximizing value of $\underline{\theta}$ is then unity. Total discounted project expenditure is given by:

$$
J=e_{0}\left[1+\frac{\Omega \alpha}{1+\alpha}\right]
$$

Proposition 3.2((ii) and (iii)) implies that total (discounted) project expenditure is maximized by some 'interior' accreditation threshold (i.e. some $\underline{\theta}$ between $\Omega$ and 1) once $\alpha$ exceeds some cut-off between 1 and 2 (i.e. the distribution of NGOs becomes sufficiently convex). It is however algebraically cumbersome and not intuitively illuminating to specify a closed-form analytical solution for this threshold value of $\alpha$. Nor is it possible to derive a transparent closed form solution for the optimal value of $\underline{\theta}$ for the general case of an interior solution (when $\alpha \neq 2$ ). Therefore, in Section 3.4 below, we shall identify a range of empirically plausible values for the key parameter in our model: the normalized benefit from accreditation $\Omega$. We shall then use these values to simulate expression (3.3) for $\alpha \in[1,2]$ and thereby identify the corresponding optimal regulation thresholds.

Remark 3.4. We have assumed in our formal analysis, summarized by Proposition 3.2, that the grant received by each accredited NGO $\left(\mathrm{e}_{1}\right)$ is independent of the number 
receiving accreditation. Our formal analysis can be easily generalized to the 'large country' case, where demand for NGOs is imperfectly elastic. Lemma 2.1 and Lemma 3.1 continue to hold as before, as do the expressions defining total discounted project expenditure (3.1)-(3.4). However, greater regulation, by reducing the number of accredited NGOs, now increases the equilibrium value of the period 1 grant (recall Figure 1). Thus, a marginal increase in regulation leads to a lower reduction in the net benefit from achieving accreditation for type L NGOs, when demand is imperfectly elastic, compared to our benchmark case of perfectly elastic demand. Such NGOs therefore acquire a greater incentive to meet the accreditation criterion. Hence, the more inelastic the demand for accredited NGOs, the lower the negative impact of a marginal increase in the accreditation criterion $(\underline{\theta})$, and, therefore, the higher the optimal level of regulation. Thus, our characterization of the optimal regulatory strategy under the 'small country' assumption of perfectly elastic demand sets the theoretical lower bound: the optimal level of regulation can only be higher when demand is imperfectly elastic. Explicit characterization of the latter case can be carried out in a manner exactly analogous to our benchmark formulation (Proposition 3.2), once a particular form is specified for the demand function. So long as our assumption $\delta\left(\frac{N_{D}(1)-c}{e_{0}}\right)<1$ continues to hold, it must always be the case that $\Omega<1$ in equilibrium. The optimal regulatory threshold must then be less than unity, as claimed in Proposition 3.2(i). However. if $\delta\left(\frac{N_{D}(1)-c}{e_{0}}\right) \geq 1$, in light of Remark 3.3, the optimal regulatory threshold level would be unity.

\subsection{Project expenditure under automatic accreditation}

Suppose now that there is no regulation. Then all NGOs get $e_{1}$ in the second period, regardless of their initial performance. Such a policy of automatic accreditation has the advantage of saving the cost of accreditation, $c$, a deadweight loss. Furthermore, since 
automatic accreditation does not screen out any NGO, it maximizes the total revenue received by the NGO sector in period 1 under elastic demand. However, these savings have to be weighed against the reduction in project expenditure by type L NGOs in period 0 . With automatic accreditation, total (discounted) project expenditure is:

$$
\begin{aligned}
J_{A}= & e_{0}\left[\int_{0}^{1} \hat{\theta}_{i} f\left(\hat{\theta}_{i}\right) d \hat{\theta}_{i}+\Omega \int_{0}^{1} \hat{\theta}_{i} f\left(\hat{\theta}_{i}\right) d \hat{\theta}_{i}+\frac{\delta c}{e_{0}} \int_{0}^{1} \hat{\theta}_{i} f\left(\hat{\theta}_{i}\right) d \hat{\theta}_{i}\right] \\
& =e_{0}\left(\frac{\alpha}{\alpha+1}\right)\left(1+\Omega+\frac{\delta c}{e_{0}}\right) .
\end{aligned}
$$

Intuitively, it is obvious that regulation will dominate automatic accreditation when the deadweight loss, $c$, is sufficiently low. To get a formal specification of exactly how low it needs to be, we shall compare (3.6) with the total (discounted) project expenditure generated by optimal NGO regulation.

\subsection{Optimal regulatory policy: general characterization}

Using (3.3) and (3.6), Proposition 3.2(i) and Remark 3.3, we immediately get the following.

Proposition 3.5. Suppose the demand for accredited NGOs in period 1 is perfectly elastic.

Then the following must hold.

(i) Given any $\Omega \in(0,1)$, automatic accreditation generates greater total (discounted) project expenditure than optimal regulation if, and only if, for every $\underline{\theta} \in[\Omega, 1)$,

$$
\left(\frac{\alpha}{\alpha+1}\right)\left[\underline{\theta}^{\alpha+1}-\tilde{\theta}^{\alpha+1}(1-\Omega)+\frac{\delta c}{e_{0}}\right]>\left(\underline{\theta}^{\alpha+1}-\underline{\theta}^{\alpha}\right) ;
$$


where $\tilde{\theta} \equiv \frac{\theta-\Omega}{1-\Omega}$

(ii) Given any $\Omega \geq 1$, automatic accreditation generates greater total (discounted) project expenditure than optimal regulation if, and only if,

$$
\alpha \delta c>e_{0}
$$

Note first that, when $\underline{\theta}=\Omega$, so that $\tilde{\theta}=0$, (3.7) reduces to:

$$
\alpha \delta c>e_{0} \Omega^{\alpha+1}
$$

Since $\underline{\theta}=\min \{\Omega, 1\}$ is always a feasible regulation strategy, by (3.8)-(3.9), Proposition 3.5 implies regulation will dominate automatic accreditation when the deadweight cost of accreditation, $c$, is sufficiently small. Proposition 3.5 further implies that given regulation, when total discounted project expenditure is maximized at $\underline{\theta}=\min \{\Omega, 1\}$, the necessary and sufficient condition for ensuring that automatic accreditation will dominate regulation is the following combination of (3.8) and (3.9):

$$
\frac{\alpha \delta c}{e_{0}}>(\min \{\Omega, 1\})^{\alpha+1}
$$

When, given regulation, total discounted project expenditure is maximized at some accreditation threshold higher than the benefit (i.e. $\underline{\theta}>\Omega$ ), (3.10) is necessary for automatic accreditation to dominate optimal regulation, but not sufficient. In either case, reversal of (3.10) is sufficient (and necessary) for regulation at $\underline{\theta}=\min \{\Omega, 1\}$ to dominate automatic 
accreditation. In general, reversal of (3.10) is sufficient, but not necessary, for optimal regulation to dominate automatic accreditation.

Remark 3.6. Recall that the optimal regulation level is necessarily higher when demand is imperfectly elastic, as compared to our benchmark case of perfectly elastic demand. Hence reversal of (3.10) is sufficient, but not necessary, for optimal regulation to dominate automatic accreditation, regardless of the elasticity of demand for accredited NGOs, when $\Omega=\frac{\delta\left(e_{1}^{*}-c\right)}{e_{0}}$, where $e_{1}^{*}$ denotes the period 1 grant level at which the donor demand for accredited NGOs is unity (recall Figure 1).

We conclude our theoretical analysis with a discussion of how bribery might affect our broad conclusions. A useful distinction is often made in the literature on bribery between extortion and corruption. The former involves forcing agents to make payments to receive goods or services which already belong to them by law. The latter involves providing agents goods or services to which they are not legally entitled, in exchange for a fee. Extortion entails an adversarial relationship between the two sides in the bribe transaction, giving the payers an incentive to complain against the receivers and expose them. Corruption, on the other hand, can benefit both parties, and does not therefore provide the bribe-payers any incentive to expose the bribe-receivers. This makes extortion easier to control. ${ }^{13}$

The possibility of bribery permitted in our model, as part of the fixed cost of accreditation $c$, involves extortion: NGOs may be forced to pay a lump-sum for accreditation, despite having already met all the legal requirements for being accredited. Thus, corruption does not explicitly figure in our model: there is no scope for NGOs who do not meet the accreditation threshold to nonetheless receive accreditation by paying bribes. In our model, all type L NGOs who apply for accreditation are observationally identical in equilibrium: they all exactly meet the accreditation threshold $\underline{\theta}$. Since the equilibrium involves pooling in this sense, the bureaucrat entrusted with processing their applications cannot tell them apart: 
consequently she must charge identical extortion payments to all such NGOs, as assumed in our model. Type H NGOs however choose their optimal project expenditure shares above $\underline{\theta}$ and thereby reveal their individual types. Could the bureaucrat charge them different extortion rates? It is difficult to see how the bureaucrat can credibly pre-commit to any extortion demand that is different from the equilibrium outcome of negotiations with individual NGOs that have already met the accreditation criterion. The gross monetary value of accreditation is identical for all such NGOs regardless of their type: this is simply the period 1 grant $e_{1}$. Hence, the bureaucrat has no incentive to charge type L NGOs that have already qualified (and thereby, in effect, incurred a sunk cost) a lower extortion payment, unless she expects type H NGOs to be less likely to successfully complain and expose her to higher authorities, the judiciary or the media. There does not appear to be any reason why this should be so: all NGOs who meet the accreditation criterion have identical incentives to contest a given bribe demand. Hence, the equilibrium bribe rate should be identical for all NGOs who seek accreditation, regardless of their type, as we have assumed. The exact level of the equilibrium bribe rate will be determined by the interplay between the cost of seeking redress for NGOs (say, litigation costs, costs of lobbying politicians, costs of making appeals to watchdog tribunals, etc.) and the cost incurred by the bureaucrat (say, job loss) due to such contestation by NGOs. ${ }^{14}$ We are, assuming, in effect, that the former is low enough to sustain an equilibrium bribe rate that permits the aggregate cost of verification, $c$, to be less than $e_{1}$.

Suppose now that we extend our model to permit bribery to take the form of corruption. With corruption, type L NGOs may choose not to meet the accreditation threshold, thereby increasing their surplus, but achieve accreditation nevertheless by bribery. However, not meeting the accreditation threshold signals the NGO's type to the bureaucrat: the choice of a lower project expenditure share reveals a willingness to pay a higher bribe for accreditation. The regulator would therefore find it rational to demand a higher bribe when 
the NGO exhibits a lower project spending. Knowing this, however, the NGO may find it rational not to reveal its type and meet the accreditation threshold instead. Consequently, we would be back to the no corruption formulation of our benchmark model. A more rigorous defence of this claim is provided in Appendix 2. Formally, as we show there, all L NGOs meeting the threshold $\underline{\theta}$ and making no corruption payment, can be sustained as a Nash equilibrium outcome of an underlying bribe-setting game. This consideration justifies and provides micro-foundations for our decision to ignore corruption and concentrate exclusively on extortion in our benchmark model.

However, all L NGOs revealing their type and paying the entire surplus as corruption bribe can also be sustained as an equilibrium outcome. In this case, since regulation merely enriches corrupt bureaucrats and imposes deadweight losses without any compensating benefits whatsoever, no regulation, i.e., automatic accreditation, necessarily dominates regulation. 'Intermediate' outcomes are also possible. In these cases, regulation generates corruption, but also improves NGO performance (see Appendix 2). Hence, regulation may dominate automatic accreditation in such an 'intermediate' equilibrium, despite corruption.

The preceding discussion yields two policy insights. First, due to the multiplicity of possible (equilibrium) outcomes clarified above, identical regulation norms can have very different welfare impacts across identical NGO sectors: they can be welfare improving in one (where they lead to some low corruption equilibrium), yet welfare reducing in another (where they lead to a highly corrupt equilibrium). Thus, we have theoretical reasons to be agnostic about the claim that bribery will necessarily make regulation counter-productive in a typical developing country context. Second, policy attention needs to be paid to minimizing bribery as it relates to illegitimate purchase of accreditation. Notice that we offer a policy emphasis very different from the concerns typically articulated by NGO spokespersons. The latter focus on the scope for extortion as an argument against regulation, whereas we (in tandem 
with the general literature on bribery) highlight corruption, which involves complicity on part of NGOs themselves, as possibly the more relevant policy concern.

\subsection{Optimal regulatory policy: numerical operationalization}

We now proceed to develop a simple numerical specification of the optimal regulatory policy that can be used to operationalize our theoretical conclusions in concrete policy contexts, by imposing empirically plausible restrictions on the parameters of the model.

In terms of the impact of accreditation on future grant flows, it is natural to expect at least a continuation of present grant values, i.e., to assume $e_{1}^{*} \geq e_{0}$, where $e_{1}^{*}$ denotes the price (i.e., period 1 grant level) at which donor demand for accredited NGOs is unity. Nominal interest rates on savings deposits, or nominal returns to investment in the capital market, are all usually below $25 \%$ in developing countries. Hence, the assumption that the time discount factor $\delta$ is not less than 0.7, i.e. an annual nominal return to savings of not more than $43 \%$, is likely to hold for all but a very few developing countries. We shall confine our attention to $\alpha \in[1,2]$. Recall that (3.10) is necessary for automatic accreditation to dominate regulation, so that reversal of that inequality yields a sufficient condition for regulation at $\underline{\theta}=\min \{\Omega, 1\}$ (and, thus, optimal regulation) to dominate automatic accreditation, regardless of the elasticity of demand (Remark 3.6). Hence, by (3.10), recalling that $\Omega \equiv \frac{\delta\left(e_{1}-c\right)}{e_{0}}$ and given $e_{1} \geq e_{0}$, optimal regulation dominates automatic accreditation if:

$$
\frac{(1-\eta)^{\alpha+1}}{\eta}>\frac{\alpha}{\delta^{\alpha}}
$$


where $\eta \equiv \frac{c}{e_{0}}$. Then, for all $\alpha \in[1,2]$ and for all $\delta \in[0.7,1]$, the RHS of (3.11) is at most $2 / 0.49$; this value occurring if and only if [ $\alpha=2, \delta=0.7]$. Consider the equation:

$$
\frac{(1-\bar{\eta})^{3}}{\bar{\eta}}=\frac{2}{0.49}
$$

The solution to (3.12) is given by $\bar{\eta} \cong 0.15$. The LHS of (3.11) is decreasing in both $\eta$ and $\alpha$, while the RHS is less than $2 / 0.49$ for all combinations $[\alpha \in[1,2)$ and $\delta \in[0.7,1]]$. Hence:

$$
\text { for all } \eta \leq \bar{\eta} \text {, all } \alpha \in[1,2) \text { and all } \delta \in[0.7,1], \text { (3.11) holds. }
$$

Noting (3.1) and (3.13), the following corollary is immediate.

Corollary 3.7. Suppose $e_{1}^{*} \geq e_{0}$, where $e_{1}^{*}$ denotes the period 1 grant level at which donor demand for accredited NGOs is unity, and suppose further $\frac{c}{e_{0}} \leq 0.15$. Then, for all $\alpha \in[1,2)$ and all $\delta \in[0.7,1]$, and irrespective of the elasticity of demand for accredited NGOs, regulation at any $\underline{\theta} \in\left[\Omega_{0}, \operatorname{Min}\left\{\Omega^{*}, 1\right\}\right]$ generates greater total (discounted) project expenditure than automatic accreditation, where $\Omega_{0} \equiv \frac{\delta\left(e_{0}-c\right)}{e_{0}}, \Omega^{*} \equiv \frac{\delta\left(e_{1}^{*}-c\right)}{e_{0}}$.

Corollary 3.7 implies, for a large and plausible range of parameter values, and regardless of the elasticity of demand for accredited NGOs, a regulation strategy $\underline{\theta} \in\left[\Omega_{0}, \operatorname{Min}\left\{\Omega^{*}, 1\right\}\right]$ dominates automatic accreditation unless its cost is above $15 \%$ of total initial revenue. Thus, the $15 \%$ cost threshold provides a convenient and simple sufficient condition, with broad 
empirical applicability and relaxed informational requirement, for assessing whether regulation is potentially efficient. ${ }^{15}$ When this condition holds, setting the accreditation threshold level equal to the discounted and normalized benefit from accreditation, or unity, whichever is lower, necessarily improves over automatic accreditation. Hence, the combination of these two conditions provides an easy to implement, broadly applicable and informationally parsimonious guide to regulatory policy.

Finally, for the special case of perfectly elastic demand (and therefore for exogenously given values of $e_{1}$ ), we identify the parametric configurations under which a regulation strategy of $\underline{\theta}=\min \{\Omega, 1\}$ not only generates greater total (discounted) project spending than automatic accreditation (recall Corollary 3.7), but also maximizes such spending, thus providing the globally optimal regulatory strategy. Given our parameter ranges $e_{1} \geq e_{0}, \frac{c}{e_{0}} \leq 0.15, \alpha \in[1,2), \delta \in[0.7,1]$, the minimum possible value of $\Omega \equiv \delta\left(\frac{e_{1}}{e_{o}}-\eta\right)$ is given by $\underline{\Omega} \cong 0.6$. Hence, $\Omega \geq 0.6$. By Corollary 3.7, regulation necessarily dominates automatic accreditation in these parameter ranges. However, a priori, it is not clear whether the optimal regulation threshold, i.e. the optimal value of $\underline{\theta}$, is equal to, or greater than, the benefit $\Omega$ (recall Proposition 3.2). A closed form solution for the optimal value of $\underline{\theta}$ is difficult to derive analytically, even for our special case of perfectly elastic demand. To identify the optimal level of $\underline{\theta}$ under various scenarios, we therefore calibrate the expression for total discounted project expenditure normalized by initial revenue, yielded by (3.3):

$$
\frac{J}{e_{o}}=\left[\frac{\alpha}{\alpha+1} \tilde{\theta}^{\alpha+1}+\underline{\theta}^{\alpha+1} \frac{1}{\alpha+1}-\underline{\theta}^{\alpha}-\tilde{\theta}^{\alpha+1} \Omega \frac{\alpha}{\alpha+1}\right]+\left(\frac{\alpha}{\alpha+1}\right)(\Omega+1) ;
$$


where $\tilde{\theta} \equiv \frac{\theta-\Omega}{1-\Omega}$, for $\alpha$ from 1 to 2 and $\Omega$ from 0.6 to 1 . We only consider $\underline{\theta} \geq \Omega$ since the optimal value of $\underline{\theta}$ cannot be less than $\Omega$ (Proposition 3.2(i)). We can consistently calibrate the expression directly since our assumption of perfectly elastic demand renders $\Omega$ independent of $\underline{\theta}$.

The calibration results are illustrated in Figure 2 below. For different values of $\Omega$ between 0.6 and 1 , we plot the project expenditure (or, equivalently, $\frac{J}{e_{o}}$ ) maximizing values of $\underline{\theta}$ corresponding to all possible values of $\alpha$ between 1 and 2 . The calibration exercise confirms our theoretical conclusions summarized by Proposition 3.2 and shows that expenditure is maximized at $\underline{\theta}=\Omega$ for values of $\alpha$ close to 1 . For every value of $\Omega$ less than 1 , the corresponding optimal value of the expenditure threshold is constant at that value of $\Omega$ up to some value of $\alpha$, say $\underline{\alpha}_{\Omega}$, and increasing in $\alpha$ thereafter. Thus, so long as $\alpha \leq \underline{\alpha}_{\Omega}$, optimal regulation involves simply putting the minimum project expenditure threshold, $\underline{\theta}$, exactly at $\Omega$. As already noted, when $\Omega$ is equal to, or greater than, 1 , the optimal expenditure threshold is unity regardless of the value of $\alpha$ (Remark 3.3). Figure 2 further shows that the minimum value of $\underline{\alpha}_{\Omega}, 1.2$, is reached at $\Omega=0.6$. Table 1 below identifies, for different values of $\Omega$ between 0.6 and 0.9 , the corresponding values of $\underline{\alpha}_{\Omega}$. These same values are also identified in Figure 2 by the upward rising concave schedule starting at $\alpha=1.2$. Given any $\Omega \in[0.95,1)$ and any $\alpha \in[1,2)$, the optimal value of $\underline{\theta}$ turns out to lie too close to $\Omega$ to demarcate it from the latter (at our sensitivity parameter 0.001 ). Thus, for all $\Omega \in[0.95,1)$, the optimal expenditure threshold lies between $\Omega$ and $\Omega+0.001$, irrespective of the value of $\alpha$. Consequently, Figure 2 only shows $\underline{\alpha}_{\Omega}$ for values of $\Omega$ between 0.6 and 0.95 . 
In practical policy contexts, it may not always be possible to get very precise estimates of $\alpha$ (i.e., the exact distribution of NGO types). However, so long as it can be ensured that $\alpha$ lies in the $[1,2)$ interval, imprecision in its estimate need not matter much in practical terms. Our calibration results, as summarized in Figure 2, show that the optimal regulatory threshold is invariably within 5 percentage points of $\min \{\Omega, 1\}$; indeed, for $\Omega \geq 0.7$, it is invariably within 2.5 percentage points of $\min \{\Omega, 1\}$. Hence, when it is known that $\alpha \in[1,2)$, but its exact value is unknown, our calibration exercise suggests that putting the minimum project expenditure threshold, $\underline{\theta}$, at $\min \{\Omega, 1\}$ provides at least a very close approximation of the optimal regulatory strategy, if not the exact optimal strategy itself. The higher the value of $\Omega$, or the lower the true value of $\alpha$, the closer the approximation.

The distribution of NGOs may also change over time. Our results show that, if it does not change too much ( $\alpha$ remains in the $[1,2)$ interval), putting the minimum project expenditure threshold, $\underline{\theta}$, at $\min \{\Omega, 1\}$ continues to provide at least a very close approximation of the optimal regulatory strategy. Thus, setting the accreditation threshold equal to the discounted and normalized benefit from accreditation, or unity, whichever is lower, which we suggest as a practical rule of thumb, is reasonably robust to relatively small variations in the distribution of NGO types as well.

\section{Insert Figure 2 and Table 1 here.}

These findings are formally summarized in the following corollary.

Corollary 3.8. Suppose the demand for accredited NGOs is perfectly elastic, with $e_{1} \geq e_{0}$, $\frac{c}{e_{0}} \leq 0.15$ and $\delta \in[0.7,1]$. Then, given any $\Omega \geq 0.6$,

(i) for all $\alpha \in[1,1.2)$, total (discounted) project expenditure is maximized by adopting the regulation strategy $\underline{\theta}=\min \{\Omega, 1\}$ 
and

(ii) for all $\alpha \in[1,2)$, the regulation strategy $\underline{\theta}$ that maximizes total (discounted) project expenditure must satisfy $[\min \{\Omega, 1\} \leq \underline{\theta}<\min \{\Omega, 1\}+0.05]$.

\section{An illustrative application to Uganda}

Uganda is an interesting application for our model of NGO regulation because many parties have raised concerns about opportunism and fund diversion in the sector. Over the past decade there have been several media reports exposing corruption and opportunistic behaviour in the NGO sector (New Vision 2006; Mukyala 2007; Anyoli 2010), and such reports have tainted public perceptions of the sector (Kwesiga 2007). The Ugandan government has expressed concern about a long list of worrying symptoms including 'briefcase' NGOs ${ }^{16}$, NGOs that change their mandate and areas of operation, NGOs that fail to submit work plans and budgets to district authorities, overcrowding in certain sectors, lack of integrity vis-a'-vis donors and intended beneficiaries and NGOs 'causing division among people or being used for political gains' (Civicus 2006, 49). Acting on these concerns, the government has sought to regulate the sector via the NGO Registration Amendment Act of 2006, the accompanying NGO Registration Regulations of 2009 and most recently the National NGO Policy of 2012. In parallel and for similar reasons, a consortium of NGOs has launched a peer review accreditation scheme, the NGO Quality Assurance Mechanism, 'to promote adherence to acceptable ethical standards and operational norms' (DENIVA and NGO Forum 2006, 3).

\subsection{NGO regulation in Uganda}

Over the past two decades the Ugandan NGO sector has witnessed strong growth in the number of organizations, from fewer than 500 in 1992 (World Bank 1994, 21) to 
approximately 7000 organizations registered at the start of $2007 .{ }^{17}$ This growth coincided with an expansion of the activities covered by the sector. Whereas NGOs' initial focus was on service delivery and awareness training, the range of activities gradually expanded to include advocacy and policy lobbying work. The government was critical of NGOs 'involving themselves in politics' and this was seen as inappropriate conduct and was also highlighted as a reason for pursuing more stringent government regulation of the sector (Wamimbi 2007). However, the 2010 national NGO policy reflects a more nuanced approach where the advocacy and government watchdog roles of NGOs are acknowledged.

Donor funds dominate the sector. Comparing Johns Hopkins University NGO sector data for Uganda and other countries, Nyangabyaki et al. (2004) show an unusually high share of private donations, including foreign aid. Dicklitch (2002) contends that the NGO sector is known to be the most lucrative sector in Uganda due to the allure of grant funds. The evidence of inappropriate and ineffective behaviour would appear to provide a strong rationale for more stringent regulation. However, due to issues around the design of regulation, there has been much opposition to the proposed regulation from local and international civil society. The government's NGO Registration Act of 1989, the NGO Registration Amendment Act of 2006 and the accompanying NGO Registration Regulations of 2009 evoke ideals such as promoting public interest, preventing fraud and guiding and monitoring organizations in carrying out their services, but in its descriptions the legislation is vague $^{18}$ and leaves considerable discretion to lower levels of government in interpreting and implementing the criteria for revoking a permit or requiring the dissolution of an NGO. The fear was that the room for discretion could be abused to threaten or close down NGOs critical of the government. Additionally, the legislation only granted NGOs the right to appeal to the Ministry of NGO Affairs, and not to an independent judiciary. 
In 2006 the Ugandan National NGO Forum and the Development Network of Indigenous Voluntary Associations (DENIVA) launched its Quality Assurance Mechanism (QuAM). QuAM is a self-regulatory scheme comprised of 59 standards and norms. Significantly, the code proposes a measure in line with project expenditure shares: that an NGO should calculate the ratio between its overheads and its programme delivery costs to assess its cost effectiveness. This is one of the code's 59 standards and principles of responsible behaviour intended to safeguard the credibility and the integrity of the sector and enhance effectiveness, accountability and legitimacy. Take up of QuAM has been slow and by 2010 only a handful of NGOs had subjected themselves to the review process (Mutungi 2010). Furthermore, as discussed in Section 1, the absence of a reliable enforcement mechanism gives reason to be sceptical of this type of self-regulation (Gugerty 2008).

While there has been much public debate around the legitimacy and credibility of these initiatives, there has been no attempt to anticipate or assess their impact. As both these schemes are ultimately funded by public money, it is essential to examine the circumstances under which returns from regulation might exceed its costs. In their current form, the government regulation scheme and the self-regulation scheme are both likely to have low impact due to problems with their implementation. Due to inadequate resource allocation, the government scheme cannot operate as envisioned in the legislation (though the national NGO policy made a commitment to rectify this situation). The QuAM is facing problems due to low take up. In light of these difficulties, the next section attempts to anticipate how an operational and effective regulation mechanism might affect the Ugandan NGO sector and society, by using Ugandan parameters to calibrate our model of regulation.

\subsection{Calibration with Ugandan parameters}


To operationalize our theoretical model, we need empirical estimates of the key parameters, viz. initial grant income $\left(e_{0}\right)$, politico-bureaucratic cost of accreditation and cost of verification $(c)$, the distribution of project expenditure shares $(\alpha)$, and the time discount factor $(\delta)$. We do this for the first three parameters for Uganda by analyzing raw data from a representative 2002 survey for the Ugandan NGO sector. This survey was based on a random sample drawn from a verified register of NGOs. ${ }^{19}$ The sample was stratified using two strata, Kampala and the rest of the country. A hundred NGOs were interviewed in Kampala and two hundred from 14 randomly selected rural districts. NGOs from the rural districts were sampled randomly with district sample sizes determined by proportionate allocation. Some findings from the survey, along with its detailed sampling methodology, are reported by Barr, Fafchamps and Owens (2005). However, the objectives of their analysis were very different. They consequently did not estimate the parameters $c$ or $\alpha$. We independently generate estimates for these two parameters, as well as that for $e_{0}$, from the raw data of their survey.

Annual revenue information is available for 199 NGOs. The median annual revenue is US $\$ 22,074$. However, due to a few NGOs with extremely high incomes, the average is $\$ 275,000$. To reduce this problem, we recalculated these values without the top $5 \%$ of NGOs. The median revenue estimate for this sub-sample of 189 is $\$ 17,261$ and the mean value is $\$ 135,307$. We accordingly take the estimate of the initial grant income, $e_{0}$, in our sample of 189 as the median revenue of $\$ 17,261$.

The highest paid bribe reported in our sample is approximately $\$ 800$. Based on a study of the Philippine NGO accreditation scheme (Soledad and Tolentino 2007), we take $\$ 200$ as the unit (per NGO) price of verification. This appears reasonable given that labour would be a major component of the direct costs and the median and mean reported per diem rates were $\$ 20$ and $\$ 66^{20}$ respectively in our data-set. We include the highest paid bribe reported as a proxy for the politico-bureaucratic extortion cost of accreditation and add these 
two estimates to derive $c$; thus $c=\$ 1000$. Hence, total cost of accreditation is estimated at less than $6 \%$ of the initial revenue; far below our $15 \%$ threshold (Corollary 3.7). This would go down further if we took the median of the full sample as our estimate for initial grant income, and would fall below $1 \%$ if we used the mean instead. Nominal interest rates in Uganda for borrowers were around $20 \%$ during our survey, yielding a benchmark time discount factor of 0.83 (well within our permissible range of $[0.7,1]$ ).

Assuming accreditation to lead to the continuation of current grant revenue in the following year $\left(e_{1}=e_{0}\right)$, and that accreditation needs to be renewed annually, we then arrive at an estimate of the present value of the benefit from accreditation: $\Omega=0.78 \cong 0.8$. Thus, our analysis suggests a project expenditure threshold of $80 \%$ as closely approximating the optimal regulatory policy in Uganda under the parametric and institutional circumstances discussed above, and under our 'small country assumption' that the Ugandan NGO sector as a whole has insignificant market power in the global NGO market (recall Corollary 3.8). Note that, by Corollary 3.7, regulation at $\underline{\theta} \cong 0.8$ dominates automatic accreditation irrespective of the elasticity of demand for accredited Ugandan NGOs. This benchmark thus sets a lower bound: the optimal project expenditure ratio can only be higher if the Ugandan NGO sector has significant market power. The same is true for an increase in grant revenue over time (i.e. $e_{1}>e_{0}$ ). As already noted, using the mean rather than the median to calculate the cost of regulation as a proportion of initial revenue would increase the estimated benefit from accreditation, and therefore imply a higher optimal project expenditure ratio as well.

Lastly, we calculated the project expenditure share for all NGOs which provided information regarding subcategories of expenditure. ${ }^{21}$ This exercise yields the distribution of project expenditure shares in our sample, from which we derive an estimate of $\alpha=1.4$ as the best fit. Our calibration results, presented in Table 1 above, imply that, at our estimated value of the gains from accreditation $(\Omega \cong 0.8)$, given our estimate of $\alpha=1.4, \underline{\theta}=\Omega$ (i.e. a 
minimal project expenditure requirement of $80 \%$ ) constitutes the optimal regulatory strategy: regulation at this threshold level dominates automatic accreditation (Corollary 3.7) and maximizes total discounted project expenditure.

Assuming uniform initial grants, we estimate the net gain in productive NGO sector expenditure, from imposing a minimal project expenditure requirement of $80 \%$, as $45 \%$ of the initial sector revenue. Estimated net gains remain sizeable even at the lower benchmark of $70 \%$, constituting $32 \%$ of the initial sector revenue. Thus, calibrating our model with Ugandan data, we find significant scope for productivity gains through regulation. These gains would be even higher if donor commitment of total funds is relatively inelastic (recall Remark 3.4). However, these estimates are based on the assumption of zero fungibility of financial categories, i.e., the assumption that the regulator can prevent NGOs from misrepresenting managerial consumption as project expenditure (whether via misleading documentation or outright bribery of lower level bureaucrats). Thus, the actual gains in practice would depend both on the extent to which donor commitment is elastic and fungibility can be restricted in any particular institutional context.

\subsection{Can community contributions regulate NGOs?}

Our analysis so far has been based on the presumption that regulation is indeed feasible, in that it cannot be evaded in practice through collusive bribe transactions between opportunistic NGOs and venal enforcers (recall the discussion of corruption in Section 3.3 above). We have accordingly concentrated on direct regulation of NGO behaviour. As noted in Section 4.1, Ugandan NGOs are largely dependent on grants from international donors for their funding, as opposed to contributions from the communities they are supposed to serve. Hence it is natural to focus on this form of regulation, given our presumption regarding its feasibility. Beneficiary communities are however often likely to be in a better informational 
position to evaluate the efficiency of an NGO, compared to distant international donors. Grant-receiving organizations may also be more bureaucratic, with higher overheads necessitated by the process of dealing with donors. If this is indeed the case, we would expect community contributions (user fees), working as market incentives, to provide an additional regulatory mechanism for enforcing NGO efficiency. This additional regulatory mechanism would also have the advantage of not providing any scope for low level bureaucrats to receive bribes from NGOs. Does our Ugandan data-set support our presumption, or our hypothesis?

At a preliminary level, we do find that NGOs dependent on community contributions tend to have significantly higher project expenditure shares than NGOs reliant on grant income. The average project expenditure shares for NGOs dependent on community contributions and grants are 0.67 vs. 0.61 respectively. The p-value of the null hypothesis assuming equal means is 0.064 . We accordingly investigate the determinants of the project expenditure share. We include two revenue source dummy variables: one to capture whether the NGO required beneficiaries to contribute to project costs in cash and/or in kind, and another indicating whether it has ever received grant funding. Following Reinikka and Svensson (2010), we include religious affiliation as a proxy for altruism. We also include a dummy for official registration and two variables capturing channels for community feedback. We add controls for sector, size and experience of the manager. Due to the censoring on the lower and upper end of the distribution, we estimate a Tobit model. The results are reported in Table 2.

\section{Insert Table 2 here.}

Our estimates support the hypotheses that: (a) regulation is feasible, and (b) beneficiary communities can subject NGOs to at least a limited form of market discipline through the instrument of user fees, thereby enhancing efficiency. NGOs with an official 
registration spend a significantly greater share of their funds on community projects, as do NGOs that charge user fees, while NGOs with grants tend to spend a significantly smaller share of their budget on community projects.

The significant positive coefficient on religious affiliation indicates that more altruistic organizations tend to devote a greater share of their funds to project expenses. Organization size is significant and negative, indicating that larger organizations tend to spend a smaller share of their revenue on projects. This is in line with previous work suggesting that as NGOs grow they may become less dynamic, more bureaucratic and less community focused (e.g. Wallace, Bornstein and Chapman 2006; Fafchamps and Owens 2009). Manager age and sectoral controls are not significant. The two indicators of community feedback channels are both insignificant.

Registration involves some benefits for NGOs, via greater credibility and therefore greater donor access; but it also involves costs, in the form of paperwork, transparency and auditing requirements, etc. Our finding regarding a positive relationship between registration and project expenditure share suggests that even this minimal form of regulation has some success in screening out more opportunistic NGOs. Since registration is a necessary part of any regulatory mechanism, it also suggests that a more extensive form of regulation, along the lines developed in this paper, need not necessarily prove counter-productive due to collusive corruption between opportunistic NGOs and low-level bureaucrats (recall the discussion of corruption in Section 3.3 above).

Our findings regarding revenue source suggest an efficiency case for greater experimentation with direct transfer of donor funds to beneficiaries, whether as cash or vouchers, so as to encourage a market for NGOs' services sustained by user fees. Thinness and fragmentation of the market in isolated rural communities, presence of cross-community externalities, lack of end-user awareness regarding the benefits of health or educational 
inputs, community-level collective action problems in organizing the acquisition of lumpy public goods, etc. might all necessitate direct donor negotiation and purchase of NGOs' services on behalf of the end-users. Direct regulation of the kind discussed in this paper would then be the natural option to consider for governments and apex donor bodies. In other cases, however, unmediated market transactions between NGOs and end-users may be both feasible and efficiency enhancing. Donors can encourage the deepening of such market transactions, through the transfer of funds directly to beneficiary communities for payment of user fees (say through school or hospital vouchers, instead of paying NGOs to run primary schools or health centres). In line with intuition, beneficiary feedback per se, when not backed by the financial inducement of user fees, appears ineffective in influencing NGO behaviour. Thus, our results suggest that end-user voice can regulate NGOs only when associated with a credible financial exit option: donors can indirectly regulate NGOs by strengthening the exit option of end-users via direct transfers.

\section{Conclusion}

This paper has developed a model which clarifies some key trade-offs in regulating NGOs, by making their future grant access conditional on prior spending of at least some minimal proportion of current revenue on direct project-related expenses. Such regulation induces at least some NGOs to increase their current project-related spending, but imposes bureaucratic costs of compliance verification, and thus deadweight losses, on all NGOs. Our model yields simple numerical rules to characterize the optimal regulatory policy in different institutional contexts.

Under a large class of empirically plausible parametric configurations, our analysis shows regulation to be potentially capable of increasing total discounted project expenditure over the level generated by a laissez faire regime of no regulation, when verification costs 
under the former constitute no more than $15 \%$ of initial revenue. This finding holds regardless of the elasticity of donor demand for NGOs' services. We have also explicitly identified the optimal regulatory policy, i.e. the optimal threshold level of project expenditure required for future grant access, under these parametric configurations, when demand is perfectly elastic. Putting the threshold project expenditure equal to the normalized present discounted gain from accreditation or unity, whichever is lower, provides either the optimal regulatory policy or a very close approximation thereof under perfectly elastic demand. Furthermore, regardless of the elasticity of demand, this regulatory rule improves over no regulation when verification costs satisfy our 'no more than $15 \%$ ' criterion. We have illustrated how our analysis can be operationalized by applying it to a large sample of NGOs from Uganda. We concluded that NGO regulation appears potentially beneficial in that context. Our focus on sufficiency conditions that identify when regulation potentially dominates automatic accreditation, our fixed coefficients specification of NGO preferences, and our assumption of perfectly elastic demand, all serve to highlight and characterize the minimal rather than the maximal, and therefore the strongest, a priori case for regulation. Our analysis also suggests a case for direct transfers by donors to end-users as a means of subjecting inefficient NGOs to market discipline.

As an easily operationalized, sufficient rule of thumb for assessing the a priori case for direct regulation, we have suggested the not-more-than $15 \%$ verification cost criterion. Available evidence suggests that objective costs of compliance verification are likely to be far below this threshold in most institutional contexts. The magnitude of costs imposed on NGOs through greater scope for politico-bureaucratic extortion remains however empirically a wide open question. As is well-known in the general literature on corruption and bureaucratic red tape, equilibrium bribe rates can vary widely, depending on institutional specificities, extent of competition among politicians and bureaucrats, bureaucrats' salaries, 
the nature of anti-corruption laws, etc. ${ }^{22}$ Empirical measurement of compliance costs in different institutional contexts, and theoretical analysis of policy formulation to minimize the scope for bribery and extortion, applying the insights thrown up by the large literature on anti-corruption policy, both constitute important areas of future research on NGO regulation.

In our analysis, we have assumed that the aim of regulation is to increase project expenditure shares. This in turn incorporates the assumption, routine in policy contexts, that project expenditure shares are strongly correlated with beneficiary satisfaction. It is usually administratively easier to monitor inputs (expenditures) rather than rigorously measure outputs (beneficiary satisfaction) in the context of NGO performance. Martens et al. (2002) find evidence of a bias among donors towards pursuing and tracking inputs because inputs are easier to monitor and measure than outputs. For similar reasons, a regulator may monitor project expenditure because it is widely perceived to be correlated with NGO effectiveness and project impact. There is evidence of such thinking in the code of Uganda's NGO quality assurance mechanism. This code proposes that an NGO should calculate the ratio between its overheads and its programme delivery costs to assess its cost effectiveness.

In practice, however, an NGO may successfully engage in cost 'padding', i.e. disguise part of its managerial consumption as programme delivery costs. Conversely, higher overhead expenditures may sometimes lead to greater efficiency in programme delivery. NGOs may also choose a service mix that caters more to donor preferences than beneficiary needs, as perceived and evaluated by the beneficiaries themselves. In these cases, higher project expenditure shares need not necessarily imply greater efficiency in programme delivery or the satisfaction of beneficiary demand. In the absence of a market for NGOs' services, it is often difficult to directly measure NGO performance in terms of responding to beneficiary demand. Bougheas et al. (2007) have shown, in the general context of charitable donations, that widely popular donor conditionalities may be inefficient, yet persist 
indefinitely. The commonly observed donor emphasis on high share of direct project-related expenses may conceivably constitute such a sub-optimal conditionality. Whether higher project expenditure shares are indeed strongly correlated with beneficiary satisfaction in different institutional contexts thus appears an open empirical question at this stage. Future work may usefully examine the strength of this correlation by devising alternative measures of beneficiary satisfaction or output performance.

Relatedly, Platteau, Somville and Wahhaj (2014) have shown that an improvement in the quality of information available to donors regarding preferences of the intended beneficiaries may increase the extent of elite capture of developmental projects. The spirit of their set-up translates in our model to a situation where the regulator can observe the true value of the project expenditure share only imperfectly, say due to cost padding. How an improvement in the quality of information available to the regulator (say through better auditing practices) affects the optimal regulatory policy and aggregate beneficiary welfare is an important question that deserves detailed theoretical investigation in future research.

Lastly, how regulation affects entry, and thereby the distribution of types in the NGO sector in the long run, is an issue we have abstracted from in our (implicitly short-run) analysis. Extensions that address this issue would evidently be in order.

\section{Appendix 1}

Proof of Proposition 3.2. From (3.3), recalling $\tilde{\theta} \equiv \frac{\theta-\Omega}{1-\Omega}$, we have:

$$
e_{o}^{-1} \frac{d J}{d \underline{\theta}}=\underline{\theta}^{\alpha}-{\frac{(\underline{\theta}-\Omega)^{\alpha-1}}{(1-\Omega)^{\alpha}}}^{(1-\underline{\theta}-\Omega)+\alpha \Omega]}
$$

(N1) yields: 


$$
e_{o}^{-1} \frac{d^{2} J}{d \underline{\theta}^{2}}=\alpha \underline{\theta}^{\alpha-1}-\frac{(\underline{\theta}-\Omega)^{\alpha-1}}{(1-\Omega)^{\alpha}}-(\alpha-1){\frac{(\underline{\theta}-\Omega)^{\alpha-2}}{(1-\Omega)^{\alpha}}}^{\alpha}[(\underline{\theta}-\Omega)+\alpha \Omega] .
$$

(i) Since $\Omega<1$ by assumption, by Lemma 2.1, the size of the NGO population that achieves accreditation when $\underline{\theta}=1$ is 0 , and it is 1 when $\underline{\theta}=\Omega$. Since $e_{1}>c$, it follows that total discounted project expenditure is higher at $\underline{\theta}=\Omega$, compared to the case under $\underline{\theta}=1$. Hence, total discounted project expenditure can be maximized only if $\underline{\theta}<1$. Notice now that (N1) implies $\frac{d J}{d \underline{\theta}}$ converges to $\frac{-e_{o} \alpha \Omega}{1-\Omega}<0$ as $\underline{\theta}$ converges to 1 . Recalling Lemma 3.1, part (i) of Proposition 3.2 follows by continuity of $\frac{d J}{d \underline{\theta}}$ in $\underline{\theta}$ in the interval $(\Omega, 1)$.

(ii) Now consider $\alpha=1$; then (N1) and (N2) reduce, respectively, to:

$$
\begin{aligned}
& e_{o}^{-1} \frac{d J}{d \underline{\theta}}=\frac{1}{(1-\Omega)}[-\Omega \underline{\theta}]<0 ; \\
& e_{o}^{-1} \frac{d^{2} J}{d \underline{\theta}^{2}}=\frac{-\Omega}{(1-\Omega)}<0 .
\end{aligned}
$$

Hence, when $\alpha=1, J$ decreases in $\underline{\theta}$ for all $\underline{\theta}>\Omega$, implying, by Lemma 3.1, that total discounted project expenditure is maximized if, and only if, $\underline{\theta}=\Omega$. Notice now that $\frac{d J}{d \underline{\theta}}$ and $\frac{d^{2} J}{d \underline{\theta}^{2}}$ are both continuous in $\alpha$. Part (ii) of Proposition 3.2 follows by continuity.

(iii) When $\alpha=2,(\mathrm{~N} 1)$ and (N2) yield, respectively: 


$$
\begin{aligned}
& e_{o}^{-1} \frac{d J}{d \underline{\theta}}=\underline{\theta}^{2}-\frac{(\underline{\theta}-\Omega)(\underline{\theta}+\Omega)}{(1-\Omega)^{2}} ; \\
& e_{o}^{-1} \frac{d^{2} J}{d \underline{\theta}^{2}}=2 \underline{\theta}-\frac{(\underline{\theta}-\Omega)}{(1-\Omega)^{2}}-\frac{(\underline{\theta}+\Omega)}{(1-\Omega)^{2}}=2 \underline{\theta}\left[1-\frac{1}{(1-\Omega)^{2}}\right]<0 .
\end{aligned}
$$

It follows from (N5) that $\frac{d J}{d \underline{\theta}}$ converges to $e_{0} \Omega^{2}>0$ as $\underline{\theta}$ converges to $\Omega$, while it converges to $-\frac{2 e_{0} \Omega}{(1-\Omega)}<0$ as $\underline{\theta}$ converges to 1 . Hence (noting (N6)), when $\alpha=2$, there must exist a unique $\underline{\theta} \in(\Omega, 1)$ which maximizes total discounted project expenditure. Since $\frac{d J}{d \underline{\theta}}$ and $\frac{d^{2} J}{d \underline{\theta}^{2}}$ are both continuous in $\alpha$, part (iii) of Proposition 3.2 follows.

\section{Appendix 2.}

\section{A Bribe-Setting Game Between NGOs and a Corrupt Regulator}

Suppose $\underline{\theta} \leq \Omega$, so that all NGOs wish to receive accreditation (Lemma 2.1(i)). Suppose an NGO $i$, of type $\hat{\theta}_{i}$, can choose any $\theta_{i} \in[0,1]$ in period 0 , but receive accreditation nevertheless by paying a corruption bribe $\beta$ if it chooses $\theta_{i}<\underline{\theta}$. Assume further, purely for algebraic simplicity, that this bribe is paid in period 0 itself. No corruption bribe needs to be paid for accreditation if $\theta_{i} \geq \underline{\theta}$ (though there may be an additional period 1 fixed cost of accreditation, $c$, perhaps involving extortion, as in our benchmark model). The corrupt regulator's strategy involves the choice of a bribe demand for each $\theta_{i} \epsilon[0, \underline{\theta})$; i.e., the choice of a bribe demand schedule $\beta\left(\theta_{i}\right)$, specified for all $\theta_{i} \in[0, \underline{\theta})$. The NGO moves first, choosing a project expenditure share and applying for accreditation. If it then faces a bribe demand, the NGO can either pay and receive accreditation, or increase its project expenditure 
share to $\underline{\theta}$ and receive accreditation without paying any bribe. Thus, NGO $i$ 's strategy involves the initial choice of a period 0 project expenditure share $\theta_{i} \in[0,1]$, along with the set of attendant choices, if $\theta_{i}<\underline{\theta}$, of whether to meet or reject any given bribe demand.

Only type L NGOs can potentially offer bribes in equilibrium. Recall that, from (2.1), the utility a type L NGO, with an optimal project expenditure share $\hat{\theta}_{i} \in(0, \underline{\theta})$, would get by meeting the accreditation criterion in period 0 is $a_{i} e_{0}(1-\underline{\theta})$, while it would get $a_{i}\left(e_{0}-\right.$ $\beta)\left(1-\theta_{i}\right)$ by choosing any share $\theta_{i} \in\left[\hat{\theta}_{i}, \underline{\theta}\right]$ and paying a bribe $\beta$. Hence, if it chooses any share $\theta_{i} \in\left[\hat{\theta}_{i}, \underline{\theta}\right]$, then the NGO's willingness to pay, i.e. the maximum bribe it would be willing to offer for accreditation, is $\beta_{\operatorname{Max}}\left(\theta_{i}\right)=e_{0}\left[\frac{\underline{\theta}-\theta_{i}}{1-\theta_{i}}\right]$. If the bribe demanded is greater than $\beta_{\text {Max }}$, the NGO is better off by not paying and meeting the accreditation criterion instead. Suppose a type L NGO adopts a strategy in the following class: choose some $\theta_{i} \in\left[\hat{\theta}_{i}, \underline{\theta}\right]$ and, if a bribe is demanded, pay if and only if it is not more than $\beta_{\text {Max }}\left(\theta_{i}\right)$. Suppose further the corrupt regulator follows a bribe-setting strategy of demanding a payment of $\beta_{\text {Max }}\left(\theta_{i}\right)$ in exchange for accreditation whenever she perceives a project expenditure share of $\theta_{i}<\underline{\theta}$. Clearly, these strategies together constitute a Nash equilibrium. Given the regulator's strategy, the NGO receives the same pay-off for all $\theta_{i} \in\left[\hat{\theta}_{i}, \underline{\theta}\right]$. The outcome where all L NGOs meet the threshold $\underline{\theta}$ and make no corruption payment can thus be sustained as a Nash equilibrium. The outcome where all NGOs reveal their true types, by choosing their respective optimal project expenditure shares and paying the entire surplus as corruption payment, can also be similarly sustained. Intermediate outcomes, involving $\theta_{i} \in\left(\hat{\theta}_{i}, \underline{\theta}\right)$ and positive corruption payment, are sustainable as well. 


\section{References}

Aldashev, G., and T. Verdier. 2010. "Goodwill Bazaar: NGO Competition and Giving to Development." Journal of Development Economics 73: 48-63.

Anheier, H.K., and L.M. Salamon. 2006. "The Nonprofit Sector in Comparative Perspective." In The Nonprofit Sector: A Research Handbook, ed. W.W. Powell and R. Steinberg. New Haven: Yale University Press,.

Anyoli, E. 2010. "NGO Chief Faces Prison Over Global Fund Money." New Vision, 26 October.

Banks, J., and R. Sundaram. 1998. "Optimal Retention in Agency Problems." Journal of Economic Theory 82: 293-323.

Bardhan, P. 1997. "Corruption and Development: A Review of Issues." Journal of Economic Literature 35: 1320-1346.

Barr, A., M. Fafchamps, and T. Owens. 2005. "The Governance of Non-Governmental Organizations in Uganda." World Development 33: 657-679.

Barro, R., and R. McCleary. 2006. "US-Based Private Voluntary Organizations: Religious and Secular PVOs Engaged in International Relief and Development, 1993-2004." NBER Working Paper No. 12238.

Bekkers, R. 2003. "Trust, Accreditation, and Philanthropy in the Netherlands." Nonprofit and Voluntary Sector Quarterly 32: 596-615.

----- 2010. "The Benefits of Accreditation Clubs of Fundraising Nonprofits." In Voluntary Regulation of NGOs and Nonprofits: An Accountability Club Framework, ed. M.K. Gugerty and A. Prakash. Cambridge, UK: Cambridge University Press.

Bougheas, S., I. Dasgupta, and O. Morrissey. 2007. "Tough Love or Unconditional Charity?" Oxford Economic Papers 59: 561-582. 
Burger, R. 2012. "Reconsidering the Case for Enhancing NGO Accountability via Regulation". Voluntas, January.

Burger, R., I. Dasgupta, and T. Owens. 2014. "Why Pay NGOs to Involve the Community?" IZA Discussion Paper No. 8051, Institute for the Study of Labor (IZA) Bonn.

Castaneda, M., J. Garen, and J. Thornton. 2008. "Competition, Contractibility, and the Market for Donors to Non-Profits." Journal of Law, Economics and Organization 24: 215-246.

Civicus. 2006. Civicus Civil Society Index Project. Civil Society in Uganda at the Crossroads? Kampala: DENIVA.

Dasgupta, I., and R. Kanbur. 2005. "Community and Anti-Poverty Targeting." Journal of Economic Inequality 3: 281-302.

DENIVA and NGO Forum. 2006. NGOs Regulating Themselves: The NGO Quality Standards. Kampala: DENIVA.

Dicklitch, S. 2002. "NGOs and Democratization in Transitional Societies: Lessons from Uganda." In Global Society in Transition: An International Politics Reader, ed. D. Nelson and L. Neack. The Hague: Kluwer Law International.

Fafchamps, M., and T. Owens. 2009. "The Determinants of Funding to Ugandan Nongovernmental Organizations." World Bank Economic Review 23: 295-321.

Ferejohn, J. 1986. "Incumbent Performance and Electoral Control." Public Choice 50: 5-25.

Greenlee, J.S., and K.L. Brown. 1999. "The Impact of Accounting Information on Contributions to Charitable Organizations." Research in Accounting Regulation 13: 111125.

Gugerty, M.K. 2008. "The Effectiveness of NGO Self-Regulation: Theory and Evidence from Africa." Public Administration and Development 28: 105-118.

Gugerty, M.K., M. Sidel, and A. Bies. 2010. "Nonprofit Self-regulation in Comparative Perspective." Nonprofit and Voluntary Sector Quarterly 39: 1027-1038. 
Guriev, S. 2004. "Red Tape and Corruption." Journal of Development Economics 73: 489504.

Hudock, A. 1999. NGOs and Civil Society: Democracy by Proxy? Cambridge, UK: Polity Press.

Kwesiga, J.B. 2007. Interview with Jassy Kwesiga (Director of Development Network of Indigenous Associations) on 13 June.

Martens, B., U. Mummert, P. Murrell, and P. Seabright. 2002. The Institutional Economics of Foreign Aid. Cambridge, UK: Cambridge University Press.

Mookherjee, D., and I.P.L. Png. 1995. "Corruptible Law Enforcers: How Should They be Compensated?" The Economic Journal 105: 145-159.

Mukyala, E. 2007. "Jinja RDC Accuses NGOs of Fraud." New Vision, 6 June.

Mutungi, B.K.K. 2010. "Improving NGO Internal Governance and Public Accountability: Sharing Experience and Cases on NGO Self-Regulation." Paper presented at the CIVICUS Webinar interaction on Legitimacy, Transparency and Accountability issues for civil society organizations, 15 July.

New Vision. 2006. "Put Donors in the Dock for Global Fund Money." New Vision, 15 November.

Nyangabyaki, B., D. Kibikyo, J-J. Barya, S.W. Sokolowski, and L.M. Salamon. 2004. "Uganda." In Global Civil Society: Dimensions of the Non-profit Sector (Vol. 2), ed. L.M. Salamon and S.W. Sokolowski. Bloomfield: Kumarian Press.

Overseas Development Institute. 1996. "The Impact of NGO Development Projects." ODI Briefing Paper 1996(2), London.

Platteau, J.-P., V. Somville, and Z. Wahhaj. 2014. "Elite Capture through Information Distortion: A Theoretical Essay." Journal of Development Economics 106: 250-263. 
Prakash, A., and M.K. Gugerty. 2010. "Trust but Verify: Voluntary Regulation Programs in Nonprofit Sector." Regulation and Governance 4: 22-47.

Reinikka, R., and J. Svensson. 2010. "Working for God: Evidence from a Change in Financing of the Nonprofit Health Care Providers in Uganda." Journal of European Economic Association 8: 1159-1178.

Riddell, R.C., M. Robinson, J.D. Coninck, A. Muir, and S. White. 1995. Non-Governmental Organizations and Rural Poverty Alleviation. Oxford: Clarendon Press.

Shleifer, A., and R.W. Vishny. 1993. "Corruption." Quarterly Journal of Economics 108: 599-617.

Soledad, F.I., and M.A. Tolentino. 2007. CSO Self Regulation: Options for Increasing Accountability. Glasgow: Civicus World Assembly.

Tinkelman, D. 1999. "Factors Affecting the Relation Between Donations to Non-profit Organizations and an Efficiency Ratio." Research in Government and Non-profit Accounting 10: 135-161.

Wallace, T., L. Bornstein, and J. Chapman. 2006. The Aid Chain: Coercion and Commitment in Development NGOs. Kampala: Fountain Publishers.

Wamimbi, R. 2007. Interview with Rosemary Wamimbi (Secretary of the NGO Registration Board) on 10 June.

Werker, E., and F. Ahmed. 2008. "What Do NGOs Do?" Journal of Economic Perspectives 22: 73-92.

World Bank. 1994. "Republic of Uganda: The Role of Nongovernmental Organizations as Community Based Groups in Poverty Alleviation." Report No. 12262-UG. 


\begin{tabular}{|l|l|}
\hline TABLE 1: $\underline{\alpha}_{\Omega}$ for a selection of values of $\Omega$ \\
\hline$\Omega$ & $\underline{\alpha}_{\Omega}$ \\
\hline 0.6 & 1.2 \\
\hline 0.65 & 1.244 \\
\hline 0.7 & 1.295 \\
\hline 0.75 & 1.355 \\
\hline 0.8 & 1.43 \\
\hline 0.85 & 1.532 \\
\hline 0.9 & 1.693 \\
\hline
\end{tabular}

\begin{tabular}{|l|r|r|r|}
\hline \multicolumn{4}{|c|}{ TABLE 2: Tobit regression of project expenditure share } \\
\hline & Coefficient & \multicolumn{1}{c|}{$\mathbf{t}$} & \multicolumn{1}{c|}{ P>|t| } \\
\hline Beneficiary contributes to cost & 0.140 & $1.95^{*}$ & 0.053 \\
\hline Grant recipient & -0.192 & $-1.92^{*}$ & 0.056 \\
\hline Religious affiliation & 0.184 & $2.12^{* *}$ & 0.036 \\
\hline Official registration & 0.231 & $1.81^{*}$ & 0.071 \\
\hline NGO asks community for feedback on NGO project & 0.095 & 1.14 & 0.255 \\
\hline Third party asks community for feedback on NGO project & -0.114 & -1.05 & 0.294 \\
\hline NGO involved in service delivery & 0.074 & 0.99 & 0.325 \\
\hline NGO involved in advocacy work & -0.026 & -0.35 & 0.729 \\
\hline Revenue & 0.000 & $-2.55^{* *}$ & 0.012 \\
\hline Age & 0.038 & 1.04 & 0.302 \\
\hline Agesquared & 0.000 & -0.96 & 0.34 \\
\hline Constant & -0.533 & -0.68 & 0.5 \\
\hline & & & \\
\hline Number of observations & & & 177 \\
\hline Sigma & & & 0.453 \\
\hline PseudoR-squared & & & 0.0755 \\
\hline Note: & & & \\
\hline
\end{tabular}

Note: $* *$ significant at $5 \%, *$ at $10 \%$. 
Figure 1: Market for accredited NGOs

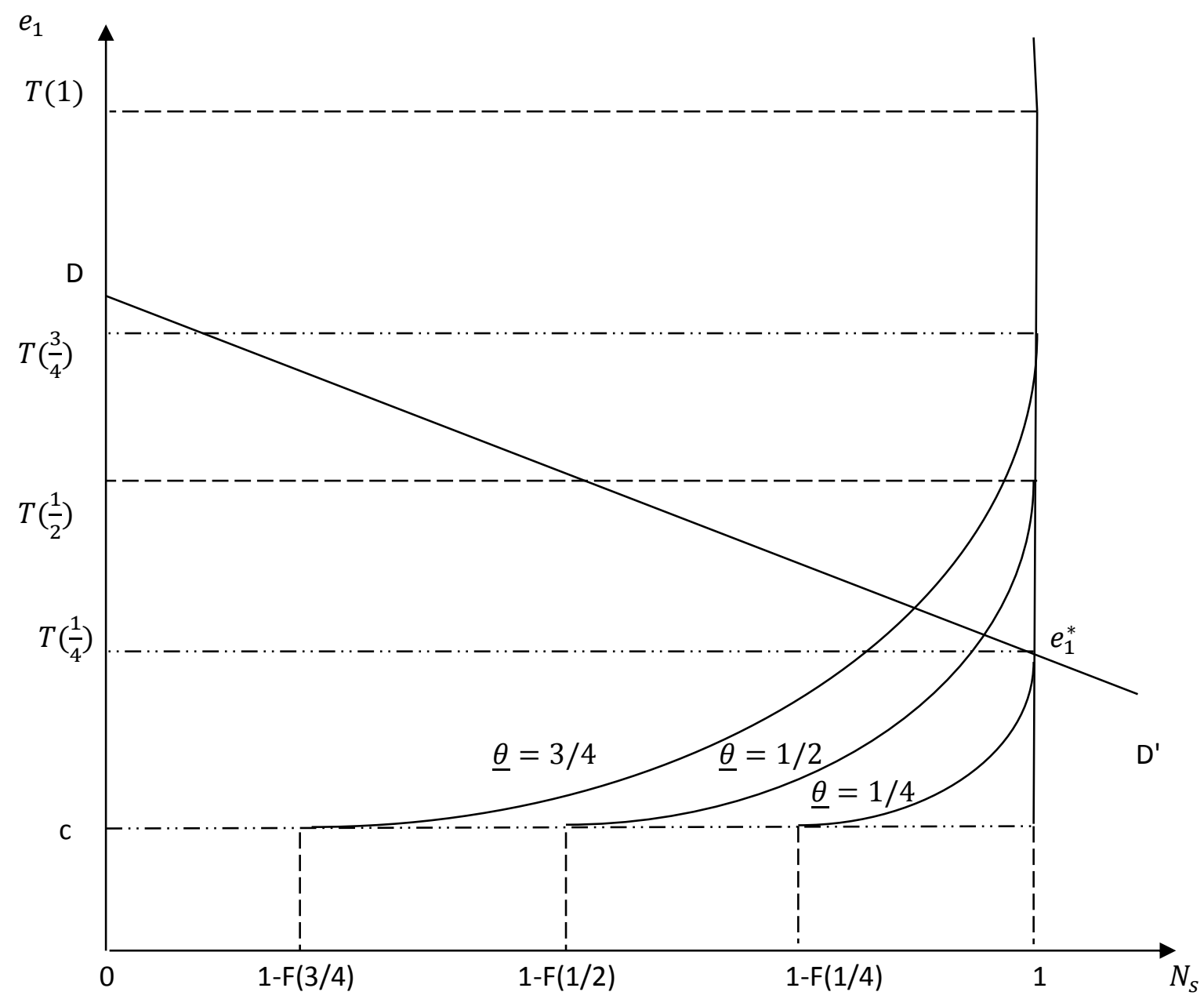

Figure 2: Plot of $\underline{\theta}$ optimizing $\mathrm{J}$ for values of $\alpha$ and $\Omega$

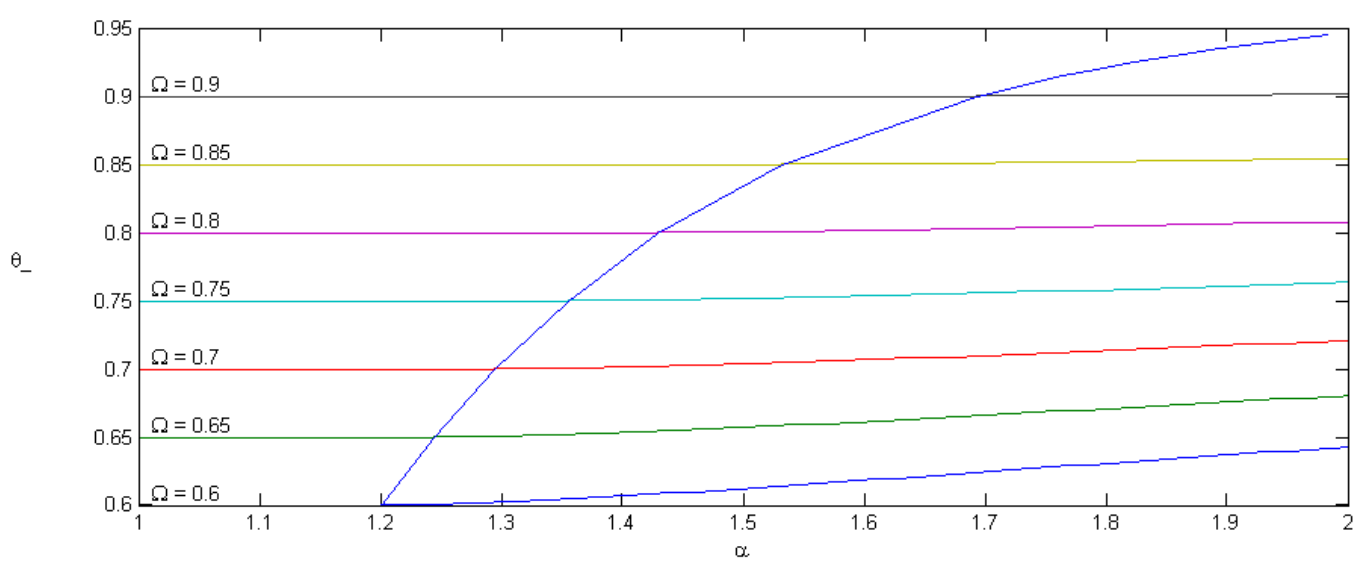

Note: The curvature of the plots for $\Omega \in[0.95,1)$ is too flat to define $\underline{\alpha}_{\Omega}$ when using a sensitivity parameter of 0.001 . 


\section{Endnotes}

1 Riddell et al. (1995) estimate that total development funds channelled via NGOs increased from $\$ 0.9$ billion in 1970 to $\$ 6.3$ billion in 1993 (1970 dollars). According to Hudock (1999), while only 6\% of World Bank projects were implemented through NGOs between 1973 and 1988, this number reached 50\% in 1994. NGOs' share of aid may be as high as $15 \%$ in developing countries (ODI 1996; Werker and Ahmed 2008). More than $40 \%$ of US overseas development funds are channelled through NGOs (Barro and McCleary 2006). NGO presence is often especially prominent in the delivery of developmental services in spheres such as micro-credit, literacy, maternal and child health, agricultural extension programmes and AIDS prevention.

2 A recent exception is Burger, Dasgupta and Owens (2014), who show that incentivizing NGOs to increase community participation may reduce the welfare of those intended by donors to benefit from the project.

3 An additional argument is that state regulation inhibits advocacy NGOs from criticizing government policies. We however abstract from advocacy NGOs to focus exclusively on service delivery NGOs. Regulation of advocacy NGOs raises a set of issues (structurally similar to those pertaining to laws governing the conduct of lobbying groups and other political organizations) very different from the ones considered here.

4 Accreditation performs essentially the same function as third party quality certification in industrial contexts and school board or university degrees in labour markets: it reduces the cost to individual donors of identifying an NGO's quality. Regulatory agencies in such analogous contexts are largely in the public sector.

5 Banks and Sundaram (1998) study a structurally related general theoretical problem, of an infinitely lived principal having to determine the optimal retention scheme when faced (under conditions that permit both moral hazard and adverse selection) with a multitude of agents, all of whom live for two periods and can be replaced in the second period. They find the principal's equilibrium retention strategy to be a cut-off rule in which an incumbent who has completed one period is retained for a second if, and only if, the first-period reward to the principal exceeds a critical ('cut-off") amount. Ferejohn (1986) derives such a cut-off rule, in the form of reelection contingent on meeting some minimum performance threshold, as the voters' optimal strategy to discipline an incumbent subject to moral hazard alone. The regulatory strategy that we focus on also constitutes a cut-off rule. However, unlike these theoretical contributions in very different contexts, we do not seek to rationalize a cut-off rule as the optimal form of regulation: regulation is simply assumed a priori to be a cut-off rule (i.e. a threshold requirement). Whether other regulatory mechanisms exist, which can improve over the optimal cut-off rule, is a theoretical issue we do not address.

6 Thus, the NGO's income in the absence of accreditation is normalized to 0 .

7 In practice, there may be some objectively, i.e. technologically, given minimal managerial consumption and overheads without which an NGO simply cannot function, so that $\underline{\theta}$ cannot objectively be set at 1 . In that case, the regulatory agency has to make an independent assessment of the extent of this minimal managerial and overhead requirement. Then $(1-\underline{\theta})$ would refer to the managerial consumption share of the NGO's revenue net of this regulator determined, technologically given, irreducible minimum managerial and overhead costs, so that whether to set $\underline{\theta}$ at 1 or some lower value remains an economic, rather than a technological, decision.

8 The model can be generalized to any finite number of periods not less than two, where an NGO receives a grant after paying the accreditation fee in any period if, and only if, it meets the threshold $\underline{\theta}$ in all the preceding periods. This does not substantively alter the conclusions we derive from our simple two-period formulation.

Our assumption regarding preferences following a fixed coefficient specification can be relaxed, say by using the CES or Cobb-Douglas form, at the cost of a major increase in algebraic complexity, without yielding any additional insights, and without changing our substantive conclusions. Greater substitutability in the utility function reduces the losses to inefficient NGOs from regulation, thereby making any given level of regulation $(\underline{\theta})$ more effective and thus increasing the level of optimal regulation. Thus, greater substitutability in NGO preferences makes it easier for regulators to change NGO behaviour in the desired direction. Hence, since we wish to identify and formulate the minimal rather than the maximal, and thus the strongest, case for regulation, we deliberately choose the fixed coefficient specification.

${ }^{10}$ Banks and Sundaram (1998) present similar findings in their very different theoretical context.

11 A monopsonistic donor choosing its own accreditation criterion, subject to the requirement of disbursing a given total grant budget equally among all NGOs who meet this criterion, evidently constitutes a special case.

12 When demand is inelastic a marginal increase in the accreditation threshold, by reducing the number of accredited NGOs, increases total NGO grant in period 1; it keeps total NGO grant in that period constant when demand is unit elastic. In either case, the pool of accredited NGOs improves, since the mean NGO type (i.e. the mean value of $\theta_{i}$ ) in the pool of accredited NGOs increases. Hence total project expenditure must increase when elasticity of demand does not exceed unity. When demand is elastic, a marginal increase in the accreditation threshold improves the pool of accredited NGOs, but reduces total NGO grant in period 1. The second effect dominates when elasticity is sufficiently close to infinity; the first effect dominates otherwise. 
${ }^{13}$ See, for example, Shleifer and Vishny (1993) for a discussion. Extortion in our sense corresponds to what they term 'corruption without theft' and corruption in our usage corresponds to their 'corruption with theft'.

${ }^{14}$ Note that we are implicitly deploying the idea of sub-game perfection in our argument here.

15 Typically, in practice, accreditation involves annual audits and external scrutiny of the expenditure pattern in the preceding year: the operational interpretation of $e_{0}$ then is the total expenditure of the NGO in the financial year for which it audits its accounts and submits the reports for external scrutiny. If accreditation involves scrutiny of expenditure over a longer period, then the empirically operational interpretation of $e_{0}$ becomes total expenditure over that entire period, discounted to its starting point.

${ }_{16}$ 'Briefcase NGOs' is a widely used term in East Africa and refers to individuals entering the sector opportunistically to receive grants, without a long term commitment to the community or the specific project. The briefcase signifies that such organizations make a minimal investment in terms of staff, office space etc., which in turn indicates the lack of a long term commitment and makes the organization difficult to track down.

17 This may overestimate the increase because not all registered organizations are necessarily operational. Some register, but never start operating. Due to staff shortages at the NGO Board, NGOs that cease operations may not be removed from the register. Nonetheless, it is clear that there has been considerable growth.

18 According to Regulation 17 (3) 'an organization may dissolve by order of the Board if the Board has reason to believe that the registered organization has not commenced its activities within twelve months from the time of registration, or without justifiable cause for any reason has ceased to exist after that, or it is proved to be defrauding the public or its members or both, or it has violated the terms and conditions attached to its permit or operated in contravention of the provisions of the Act; or for any other reason the Board considers necessary in the public interest'.

19 The official NGO register was updated and verified using information from the NGO forum, lists from umbrella/network organizations, the phonebook, information from faith-based organizations that hold contact details of NGOs with whom they work, and, at the district level, lists held by local governments on all NGOs which operate in their area. In addition, letters were sent to PO Box addresses and there was a radio appeal made asking registered NGOs to call and update their contact information. Contact was then made by telephone, and if that failed a visit was made to the physical address. The 14 districts included in the survey sample (selected out of 55 non-Kampala districts) were Arua, Busia, Iganga, Jinja, Kabale, Kasese, Kibaale, Lira, Luwero, Mbale, Mbarara, Mukono, Rakai and Wakiso. An NGO was classified as being part of a particular district if its headquarters were in that district.

${ }^{20}$ We calculated these values after omitting the highest $1 \%$ of reported per diem rates.

21 We defined project expenditure to include direct project expenses and salaries of project staff, allowances paid to staff and beneficiaries, payments to NGOs and other organizations and fuel costs. We excluded overheads such as administrative staff, rent and equipment.

22 See Shleifer and Vishny (1993), Mookherjee and Png (1995), Bardhan (1997) and Guriev (2004). 